San Jose State University

SJSU ScholarWorks

Master's Theses

Master's Theses and Graduate Research

1995

\title{
Mexican American perspectives on independence and role fulfillment of people with disabilities : an adapted study
}

Leslie Michelle Major Auer

San Jose State University

Follow this and additional works at: https://scholarworks.sjsu.edu/etd_theses

\section{Recommended Citation}

Major Auer, Leslie Michelle, "Mexican American perspectives on independence and role fulfillment of people with disabilities : an adapted study" (1995). Master's Theses. 1115.

DOI: https://doi.org/10.31979/etd.xc96-pyp8

https://scholarworks.sjsu.edu/etd_theses/1115

This Thesis is brought to you for free and open access by the Master's Theses and Graduate Research at SJSU ScholarWorks. It has been accepted for inclusion in Master's Theses by an authorized administrator of SJSU ScholarWorks. For more information, please contact scholarworks@sjsu.edu. 


\section{IPFORMATION TO USERS}

This manuscript has been reproduced from the microfilm master. UMI films the text directly from the original or copy submitted. Thus, some thesis and dissertation copies are in typewriter face, while others may be from any type of computer printer.

The quality of this reproduction is dependent upon the quality of the copy submitted. Broken or indistinct print, colored or poor quality illustrations and photographs, print bleedthrough, substandard margins, and improper alignment can adversely affect reproduction

In the unlikely event that the author did not send UMI a complete manuscript and there are missing pages, these will be noted. Also, if unauthorized copyright material had to be removed, a note will indicate the deletion.

Oversize materials (e.g., maps, drawings, charts) are reproduced by sectioning the original, beginning at the upper left-hand corner and contiming from left to right in equal sections with small overlaps. Each original is also photographed in one exposure and is included in reduced form at the back of the book.

Photographs included in the original manuscript have been reproduced xerographically in this copy. Higher quality $6^{n} \times 9^{n}$ black and white photographic prints are available for any photographs or illustrations appearing in this copy for an additional charge. Contact UMI directly to order.

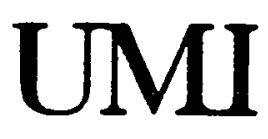

A Bell \& Howell information Company 300 North Zeeb Road. Ann Arbor. MI 48106-1346 USA $313: 761-4700 \quad 800: 521-0600$ 


\title{
MEXICAN AMERICAN PERSPECTIVES ON \\ INDEPENDENCE AND ROLE FULFILLMENT OF PEOPLE WITH DISABILITIES:
}

AN ADAPTED STUDY

\author{
A Thesis \\ Presented to \\ The Faculty of the Department of Occupational Therapy \\ San Jose State University \\ In Partial Fulfillment \\ of the Requirements for the Degree \\ Master of Science
}

by

Leslie Michelle Major Auer

December, 1995 
UMI Number: 1377206

UMI Microform 1377206

Copyright 1996, by UMI Company. All rights reserved.

This microform edition is protected against unauthorized copying under Title 17, United States Code.

\section{UMI}

300 North zeeb Road

Ann Arbor, MI 48103 
C $\mathbf{1 9 9 5}$

Leslie Michelle Major Auer

ALL RIGHTS RESERVED 
APPROVED FOR THE DEPARTMENT OF OCCUPATIONAL THERAPY

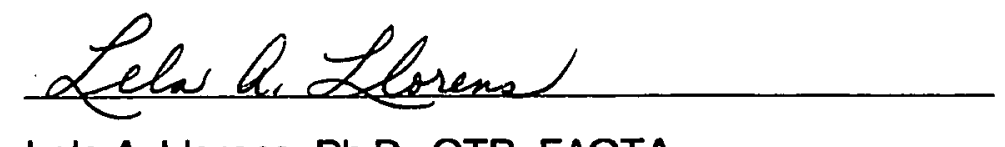

Lela A. Llorens, Ph.D., OTR, FAOTA

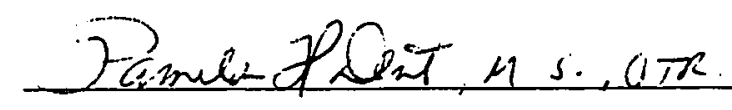

Pamela H. Dent, M.S., OTR

Dink Prolidirg

Deborah Balding, M.S., OTR

APPROVED FOR THE UNIVERSITY

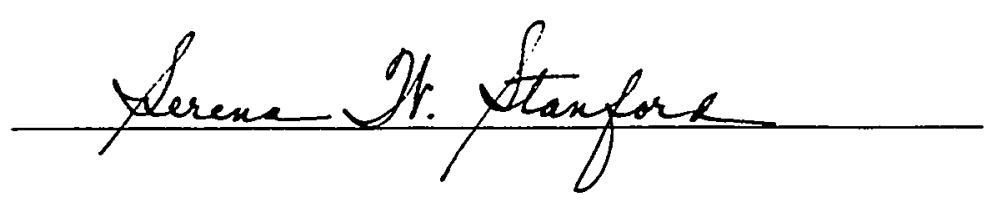




\section{ABSTRACT \\ MEXICAN AMERICAN PERSPECTIVES ON ROLE FULFILLMENT AND INDEPENDENCE OF PEOPLE WITH DISABILITIES: \\ AN ADAPTED STUDY}

\section{by Leslie Michelle Major Auer}

Perspectives of Mexican Americans on independence and dependence of people with disabilities in the home and community and the meaning of specific activities that derive from occupational roles of importance in everyday life were explored.

The data were obtained from questionnaires administered to 25 selfreported Mexican American subjects. Responses indicated strong feelings of loyalty and responsibility to assist family members who have disabilities. Results suggested that: Mexican Americans who are disabled may be less inclined to demonstrate significant strides toward independence because of cultural values that support interdependence within the family and acceptance of support outside the family is a progressive step for many Mexican American families; Mexican Americans may find training for independent performance of toileting, eating, and bathing more important than other ADL, and may consider roles of "values teacher" for younger and older men and women, and "school student" for teenagers and children more important roles than others. 


\section{ACKNOWLEDGEMENTS}

This author wishes to express sincere gratitude to all the people who gave support for the completion of this study. A sincere "thank you" especially goes out to Lela A. Llorens, Ph.D., OTR, FAOTA, of the San Jose State University, Department of Occupational Therapy for being the primary advisor for this study; to Deborah Bolding, M.S., OTR, Clinical Director for Occupational Therapy at Lucille Salter Packard Children's Hospital at Stanford for being a reader for this study; and to Pamela Dent, M.S., OTR, an Occupational Therapist currently working in Home Health and former therapist at CASA MACSA (a day treatment facility primarily serving the needs of elderly Mexican American clients in the San Jose community) for being a reader for this study.

This author would also like to thank Dorothy R. Stearns, M.S., OTR, Occupational Therapist for the Comprehensive Rehabilitation unit at the VA Medical Center in Palo Alto, California, for her contribution to the original idea for this study and her encouragement.

Finally, this author wishes to thank family members and friends for their constant encouragement, ideas, and support throughout the extent of this project. 


\section{TABLE OF CONTENTS}

ABSTRACT

ACKNOWLEDGEMENTS U v

LIST OF TABLES $\quad x$

CHAPTER ONE: INTRODUCTION

Purpose 1

Research Problem 1

Research Questions 3

Definitions 3

Significance of the Study

Assumptions $\quad 5$

$\begin{array}{ll}\text { Limitations of the Study } & 6\end{array}$

CHAPTER TWO: REVIEW OF LITERATURE $\quad 8$

$\begin{array}{ll}\text { Cultural Considerations for Occupational Therapy } & 8\end{array}$ and Health Care

Cultural Considerations for Mexican Americans and Hispanics $\quad 12$

Mexican American Health Care Practices, $\quad 13$

Cultural and Religious Beliefs

Mexican American Family Role in Health Care and Rehabilitation 15

Mexican American Social Roles by Gender $\quad 17$

$\begin{array}{ll}\text { Mexican American Community and Physical Disability } & 18\end{array}$

$\begin{array}{ll}\text { Theoretical Perspective and Conceptual Framework } & 18\end{array}$

$\begin{array}{lr}\text { Stearn's Research } & 20\end{array}$

$\begin{array}{ll}\text { Summary } & 21\end{array}$ 
CHAPTER THREE: RESEARCH DESIGN AND METHODOLOGY 23

Survey Methodology 23

Instrument Development 24

Subjects and Sampling $\quad 25$

Data Collection 26

Data Analysis 26

CHAPTER FOUR: DATA AND RESULTS 28

Demographic Data 28

Age and Gender $\quad 28$

Residency Status $\quad 28$

Present Level of Education $\quad 29$

Religion $\quad 29$

Perspectives on Disability as a Person with a Disability 29

Independence with Activities of Daily Living 29

Preference Regarding Familial Relationships and Gender $\quad 33$ of Caretakers and Therapists

Perspectives on Disability as a Parent 36

Parental Assistance for a Child with a Disability 36

The Most Influential Person in the Decision of 43

Lending Assistance to a Child with a Disability

Perspectives on Disability as a Son or Daughter 44

Child's Assistance of a Parent with a Disability 44

The Most Influential Person in the Decision 51

of Lending Assistance to a Parent with a Disability

Social Roles in Community Life 52 
Social Roles for a Mexican American Man 54

Social Roles for a Mexican American Woman 55

Social Roles for an Older Mexican American Woman 55

Social Roles for an Older Mexican American Man 58

Social Roles for a Male Mexican American Teenager 60

Social Roles for a Female Mexican American Teenager 62

Social Roles for a Male Mexican American Child 62

Social Roles for a Female Mexican American Child 65

Goal of Rehabilitation 67

Having a Person with a Disability in the Family 67

Use of Community Based Programs 69

$\begin{array}{ll}\text { Results } & 70\end{array}$

CHAPTER FIVE: DISCUSSION OF RESULTS, PROFESSIONAL IMPLICATIONS, RECOMMENDATIONS, AND CONCLUSIONS

Independence in Activities of Daily Living 77

Perspectives of a Person with a Disability 77

$\begin{array}{ll}\text { Perspectives of the Family Member } & 78\end{array}$

Quality and Amount of Assistance $\quad 80$

Preference Regarding Familial Relationship $\quad 80$ and Gender of Caretakers and Therapists

Influential Individual in the Family's Decision 81 to Offer Assistance

Social Roles in Mexican American Community Life 82

Goal of Rehabilitation $\quad 84$ 
Use of Community Based Programs for People with Disabilities $\quad 85$

Implications for the Profession $\quad 86$

$\begin{array}{ll}\text { Recommendations } & 90\end{array}$

$\begin{array}{ll}\text { REFERENCES } & 93\end{array}$

$\begin{array}{ll}\text { APPENDIX: Questionnaire } & 99\end{array}$ 


\section{LIST OF TABLES}

1. Activities of Daily Living Most Desired for Independence by a Person with a Disability

2. Acceptance of Assistance in ADL by a Person with a Disability 32

3. Felt Obligation to Accept Assistance in ADL 34 by a Person with a Disability

4. Preferred Familial Relationship and Gender of Caretakers for a Person with a Disability

5. Preferred Gender of Therapist for Self-Care Activities Training 37

6. Parental Assistance with ADL 40 for a Child with a Disability

7. Expectation for Independent Performance in ADL 42 for a Child with a Disability

8. The Most Influential Person in the Decision to Lend Assistance to a Child with a Disability

9. Child's Assistance with ADL for a Parent with a Disability

10. Expectations by a Child for ADL Performed Independently by a Parent with a Disability

11. The Most Influential Person in the Decision to Lend Assistance to a Parent with a Disability

12. Important Social Roles for a Mexican American Man 56

13. Important Social Roles for a Mexican American Woman 57

14. Important Social Roles for an Older Mexican American Woman 59

15. Important Social Roles for an Older Mexican American Man 61

16. Important Social Roles for a Male Mexican American Teenager 
17. Important Social Roles for a Female Mexican American Teenager 64

18. Important Social Roles for a Mexican American Male Child 66

19. Important Social Roles for a Mexican American Female Child 68 


\section{CHAPTER 1 \\ INTRODUCTION}

\section{Purpose}

The present study was an adaptation of the Master's thesis by former occupational therapy student, Dorothy Stearns (1988) on "Vietnamese Perspectives on Independence and Role Fulfillment of the Disabled." People of Mexican American origin were the population on which this present research was focused in order to obtain a better understanding of the cultural perceptions of disability within the Mexican American community. More specifically, this study was aimed at determining the importance and meaning of certain activities of daily living and skills in the lives of Mexican American people, perceptions of Mexican Americans on issues of dependence and independence of people with physical disabilities in the home environment, and role expectations in the community for the general population of Mexican Americans at different ages across the lifespan. It was the expectation that knowledge about these areas can be translated into a more culturally sensitive practice of occupational therapy.

\section{Research Problem}

The need for cross-cultural research has come in response to the research findings of physicians and other health care practitioners, in various specialty areas, who found that cultural factors played an important role in eliciting patient histories, establishing diagnosis, obtaining the help and cooperation of the patient's family and friends, and in convincing patients to adhere to recommended courses of treatment (Clark, 1983). The need for such 
research was also supported through relevant statistics that show, according to the 1990 census, the population of people of Hispanic origin in the United States dramatically increased to about $9 \%$ of the total population. It was also estimated by the United States Bureau of the Census, that by the year 2000 , people of Hispanic origin will become the largest minority group represented in this country (Caudle, 1993). In California alone, Mexican Americans predominate, compromising $60 \%$ of the Hispanic population (Giachello, 1985). In Santa Clara County, the Hispanic population has grown $38.8 \%$ since 1980 to become the county's largest ethnic minority (Lewis, 1991). Given such statistics, health care, including occupational therapy, for Hispanics is and will continue to be a growing concern, with the possibility of misinterpretation of their cultural beliefs and values becoming greater (Caudle, 1993). The census statistics show and McCormack, Llorens, and Glogoski (as cited in Kiernat, 1991) reported that ethnic minorities are highly undeserved in health care. The Mexican American community is the fastest growing ethnic group in the United States (Gann \& Duignan, 1986), and there is a shortage of research available on the beliefs, behavior, customs, and family roles regarding health and disability/illness of people of Mexican American origin. It has become increasingly necessary to study this subgroup. Further research of Mexican Americans is also needed so that clinicians' understanding and knowledge will reflect more cultural sensitivity, so that more cost effective, quality care can be assured for this segment of the population. 


\section{Research Questions}

The following questions posed for this study were adapted from the Stearns (1988) study to facilitate greater relevancy to the Mexican American sample studied:

1. What are the Activities of Daily Living that Mexican American people believe to be the most important to perform independently by a person with a disability?

2. What are the perceptions held by Mexican Americans regarding independence of a person with a disability in the family, quality of assistance given, and amount of assistance provided?

3. What do Mexican Americans consider to be the primary social roles of older adult males and females over 60 years of age, of adult males and females ages 20 to 59 years, and of teenagers and boys and girls ages 0 to 19 years?

4. What do Mexican Americans perceive as the primary goal of rehabilitation for a person with a disability at different ages across the lifespan?

5. What are the perceptions of Mexican Americans toward the use of community based resources for people with disabilities?

\section{Definitions}

The following definitions have been generated for this study.

1. Activities of Daily Living (ADL): Tasks that are a regular part of a person's day. Specifically addressed in this study are eating, child care, grooming, operating a car or wheelchair, meal preparation, bathing, house maintenance, dressing, toileting, and housekeeping. 
2. Anglo American: Non-Hispanic Caucasian

3. Assistance: Help or aid.

4. Community based resources: programs available for people with disabilities outside the home.

5. Cultural tendencies: The life ways to which a particular population or cultural group subscribes.

6. Disability: The loss of function relative to physical, psychological, social and developmental demands (World Health Organization, 1980).

7. Hispanic: term used to describe people of Latin American or Spanish ancestry.

8. Independent: With no assistance from another person. Yet, may involve the use of assistive devices by the individual him/herself.

9. Mexican American: Person of either Spanish and American Indian descent, or mixture of Spanish, American Indian, and African American descent, or a descendent of ancestors who have lived in the United States for over 300 years (Downes, 1994).

10. Primary social roles: The most valued behavior patterns appropriate to a given community. In this case, those roles most valued by the Mexican American community.

11. Rehabilitation: The process of restoring a person's ability to live and work as independently as possible after a disabling injury or illness (O'Toole, 1992).

12. Role: The expected behaviors, both externally and internally determined, associated with a particular status or position that one occupies in 
a social system (Hopkins \& Smith, 1988).

\section{Significance of the Study}

This researcher was interested in discovering the Activities of Daily Living, as taught by occupational therapists, that are considered relevant in the Mexican American home and community settings. It was considered that such a study might bring a better understanding of what is meaningful to this ethnic group into accord with what is prescribed for patients of this ethnic group, and thus, increase patient compliance. It is important to bring the concept of culture, as it is relevant to practice, to the attention of occupational therapists so that they can monitor its influence on patients' behavior and on their own decision making process when prescribing treatment.

Burke (as cited in Stearns, 1988) brings the role of culture into her definition of occupation:

[Occupation is] a behavior which is motivated by an intrinsic, conscious urge to be effective in the environment in order to enact a variety of individually interpreted roles that are shaped by cultural tradition and learned through the process of socialization (p. 8).

Gaining insight into how different occupational activities are defined, valued, and organized by diverse ethnic groups adds to the clinician's value as an effective therapist.

\section{Assumptions}

The assumptions for this study were:

1. Successful occupational therapy is contingent upon the awareness of different cultural values and expectations for independence or dependence of 
people with disabilities within the home and community environments.

2. Successful occupational therapy and a positive, working clienttherapist relationship is contingent upon the awareness of different cultural roles of patients with a disability in their community and home environments.

3. The questionnaire was credible for the Mexican American population targeted.

4. The Mexican American subjects who returned a completed questionnaire were as accurate and honest as possible in the information they provided.

\section{Limitations of the Study}

The anticipated limitations of this study included:

1. The requirement of literacy in English for the completion of the questionnaire and the recruitment of presumably "educated" subjects from San Jose State University's academic departments and Latino clubs on campus automatically limited the number of otherwise reliable Mexican American participants in the Santa Clara County community (ie. those who are not English literate or who are not college educated). This created the situation for a sample that was not truly representative of the whole Mexican American population that could have been studied.

2. As in general, the Mexican American participants in this study may have viewed the intentions of this European American researcher with suspicion, thus biasing the results.

3. Those participants who were unfamiliar with the survey questionnaire method used to collect data might have felt uncomfortable completing and/or 
returning the questionnaire. Such a situation could have limited the number of participants.

4. Due to the non-randomized population sample for this study, findings are not generalizable.

5. Efforts to shorten the overall length of the questionnaire may have reduced the space for written responses to open-ended questions which could then have influenced the length and substance of the responses.

6. In order to actively obtain unbiased information, the opportunity for write-in responses was given for almost every question posed. However, this manner of collecting data might have limited the possibilities for statistical analysis. 


\section{CHAPTER TWO \\ REVIEW OF THE LITERATURE}

This review of the literature presents some basic cultural considerations that are important to occupational therapists as health care providers, compares the Mexican American Hispanic population to other Hispanic immigrant groups in the United States, presents and describes predominant Mexican American cultural and religious beliefs and values, as well as describes how these beliefs and many of their culturally based health care practices relate to Western medicine. At the same time, this review will address specific social roles (including gender based roles) held within the Mexican American family and community. Also, a delineation of the occupational therapy frame of reference used for this research is presented with concentration placed on the independence of people with disabilities performing activities of daily living. Finally, the main ideas for this review and thesis are presented as they were derived and adapted from the Stearns (1988) study.

\section{Cultural Considerations for Occupational Therapy and Health Care}

The United States has grown to be a large multicultural society. With the population of ethnic minorities growing steadily, a recent study suggested that the White majority will eventually become the numerical minority (Wilson \& Gutierrez, 1985). Demographic changes have lead to increased awareness of cultural differences between patients and practitioners on the provision of health care services (Berlin \& Fowkes, 1983). Occupational therapists have historically followed the western medical tradition that primarily reflects the 
views of the dominant Anglo American culture which values independence, and that completely separates a person's disability from his or her cultural or world view (Lea, 1994; Barney, 1991). Consequently, patients are assessed and treated with little or no regard to the effects of culture or racial background on their therapeutic process (Pope-Davis, Prieto, Whitaker \& Pope-Davis, 1993). Recent research has shown that appropriate provision of services can occur only if the cultural diversity of patients and the interaction of the various cultural backgrounds of patients and staff are taken into account (Caudle,1993; Dillard et al., 1992; Fitzgerald, 1992). Also, it has been observed that many aspects of culturally patterned behavior are not an integral part of the medical system of which occupational therapy is a part. Yet, culture plays an integral role in health care and the types of health problems most often found. According to Clark (1983), a substantial amount of literature supports the correlation between culture and health status in the following areas: cultural aspects of diet; socialization of children; types of exercise engaged in; sexual beliefs and behavior; the balance of work, rest and play; rituals and religious practices; and many other activities of daily living.

According to Caudle (1993) and Giachello (1985), obstacles for Mexican Americans who receive adequate health care have included language barriers, class and cultural disparities, health care providers who are viewed as more interested in money than patient welfare, a lack of Mexican American doctors and other health care providers (including occupational therapists) in demographic areas where Mexican Americans live, long waiting times for care, lack of coordination between social services and health care facilities, and 
discrimination. However, a new trend of cultural sensitivity is emerging and health care practitioners, including occupational therapists, are faced with a new challenge. The acknowledgement and incorporation of culture in treatment practice is now considered imperative for the safe and effective delivery of rehabilitation and other types of health care.

Presently, the official definition for licensure of occupational therapy states (as cited in Padilla, 1994), "Occupational therapy is the use of purposeful activity with individuals who are limited by physical injury or illness, psychosocial dysfunction, developmental or learning disabilities, poverty and cultural differences, or the aging process in order to maximize independence, prevent disability and maintain health" (p.14). Using this definition of purposeful activity assumes that the therapist who is treating the patient will incorporate activities that have meaning or "purpose" for the patient. This definition also assumes that the patient derives meaning from his/her culture. In order to understand some of the roles and values of Mexican Americans, it is necessary to analyze the activities in which they frequently engage from the perspective of their culture. Such information is essential for the occupational therapist who desires maximal compliance with treatment and better therapeutic outcomes.

Culture is a learned, yet constantly changing behavior orientation that emphasizes the attitudes, values, beliefs, customs and personality of a particular group of people (Casas \& Ponterotto, 1991; Davidson, 1991). Added to this, Ogbu (1987) pointed out that "it is culture which shapes the way of life shared by members of a population" (p.156). Bauwens and Anderson (1992) described all belief systems as "culture-bound" because "they are based 
on cultural factors and tied to the meaning that individuals ascribe to these factors" (p. 307). As health care providers, occupational therapists who are committed to serving the culturally diverse population of the United States should strive to be aware of, sensitive to, and respectful of variances in cultural beliefs (Anderson, 1989). Individual cultures, including Mexican American culture, may have varying perceptions regarding expected behavior, etiology of illness or disability, help-seeking tendencies, coping patterns, and treatment practices (Kraft, 1979). According to Smart and Smart (1991), "the degree of acceptance of disability may influence decisions to apply for services and the success of the entire rehabilitation process" (p.357). Linkowski (1987) pointed out that, "acceptance of disability is assumed to be an important mediating variable (which) can assist researchers and practitioners in understanding the connection between the person's disability and self-perception and in predicting independent living, educational, and vocational rehabilitation program-related outcomes" (p. 1). Therefore, it is necessary for rehabilitative clinicians to have an understanding of cultural variations so that appropriate treatment can be prescribed or performed.

Anderson (1989), who conducted a study of programs that assist ethnic families with disabled family members, has directed health care administrators to some of the cultural issues which frequently arise regarding treatment efforts, and how to better serve families of various ethnicities in culturally relevant, appropriate and effective ways. She articulates the importance, when working with various cultures, "to remember that cultures are not static entities and that cultural tendencies are in no way fixed or rigidly adhered to by any one 
individual or family" (p.168). In fact, Anderson (1989) feels that "to ascribe to cultural tendencies (the life ways that a population subscribes to) a more deterministic role results in potential stereotyping of ethnic and racial minorities or majorities" (p.168). It is also important, when working with the concept of culture, to avoid grouping populations so broadly that biases and stereotypes are indicated from the onset (Anderson, 1989).

\section{Cultural Considerations for Mexican Americans and Hispanics}

It has become necessary to clarify the term "Hispanic," which is often misleading and used to denote commonality among people who, in actuality, are different. The term "Hispanic" actually refers to people of Spanish descent and is different than the term "Latino," which refers to people of Latin America (Downes, 1994). However, this researcher has found that the term "Hispanic" has typically been used in the literature and statistical data referenced to describe people of Latin American or Spanish descent without any difference noted. Yet, there are distinctions that should be acknowledged within these two subgroups. For example, there are five major groups which are categorized as Latino. These are Puerto Ricans, Cubans, Central and South Americans, and Mexican Americans. Although they are often considered to be homogeneous, there are certain factors which distinguish the different groups. Many people of Latin America, including Mexican Americans, are of Spanish and Indian descent and are commonly referred to as "mestizos" (Downes, 1994). "Mulatto" is the term used to describe "a heritage of Spanish, American Indian, and African American" (Downes, 1994, p. 63), a heritage to which many Mexican 
Americans also belong. According to Downes (1994), “a Mexican American may [also] be a descendant of ancestors who have lived in the U.S. for over 300 years (Chicano), or may have entered the U.S. more recently as a legal 'green card' holder (Bracero), or entered illegally" (p. 63).

In the United States and in California, Mexican Americans are the largest Hispanic (referring to the statistical definition) group (Smart \& Smart, 1991), and have historically lived with a high degree of stress and anxiety associated with their low socioeconomic class and minority status which often excludes them from the benefits of full participation in social services available to the American public (Hanline \& Daley, 1992). However, to assure better treatment of its ethnically diverse citizens, the United States passed legislation in 1974 in the form of the Health Planning and Resources Act, which mandated increased cultural awareness when a health care facility plans for the health care needs of cultural minorities (Schreiber \& Homiak, 1981). Also, Congress expanded Medicaid to cover health care costs for low income children (Short \& Lefkowitz, 1992), which automatically affects many Mexican American families who need financial help to cover the costs of supporting their children who have disabilities.

\section{Mexican American Health Care Practices, Cultural and Religious Beliefs}

The beliefs and practices discussed in the following primarily come from the Mexican American culture but carry over into other Latino cultures in many instances. Downes (1994) pointed out that Mexican Americans are the least likely of any ethnic minority to access Western health care services for reasons 
stemming from lack of health insurance to language barrier problems, and thus may continue to practice the healing customs of their country of origin when aid is unobtainable. According to Downes (1994), illness is commonly seen as a punishment from God for sins committed, and may necessitate consultation with a "curandero" for healing treatments through prayers and rituals. Given that the majority of Latin American people practice the Roman Catholic religion, praying to God and saints for healing and protection is common practice according to Monroy (as cited in Downes, 1994). Along these same lines, it is common among Mexican American people to believe that a person's fate is under the control of outside forces (Harris \& Moran, 1987), and that the only way to control supernatural forces is through practices of magic or through prayer (Maduro, 1983).

Another cause of illness, according to McCormack, Llorens and Glogoski (cited in Kiernat, 1991), comes from having intense emotional states which can cause imbalances in the body. Such imbalances are traditionally treated through a holistic healing practice called "curanderismo" (Maduro, 1983). The whole family, together with the "curandero," provides "psychological, physiological, social, and spiritual support" (Glogoski, Llorens, \& McCormack cited in Kiernat, 1991, p. 13) to the ill family member. Any imbalance produced in the body that causes illness is attributed to a coexisting imbalance of "hot" or "cold" substances in the body (Downes, 1994). Curing an imbalance, under this philosophy of practice, involves the use of foods, beverages, and herbs classified as either "hot" or "cold," which can return the body to its original, healthy balanced state (Downes, 1994). McCormack, 
Llorens, and Glogoski (1991) provide the example that "hot" illnesses (i.e., fevers, rashes, and nausea) are cured by ingesting "cold" substances such as cilantro, fresh fruits, and milk products, whereas "cold" illnesses (i.e., colds, flu, rheumatoid arthritis, or muscle spasms/contractures) can be cured by ingesting "hot" substances such as chili peppers and other spicy foods.

One of the most important cultural factors related to health care practices is "personalismo" or the sense of strength for healing derived from close, personal interaction (Cuellar, 1988). Such personalization can be seen in the patient's relationship to the traditional "curandero," who is perceived as a knowledgeable friend, neighbor, or relative (Downes, 1994). Such close interaction with the patient provides for maintaining dignity and pride for that patient, as well as establishing trust and rapport which can facilitate compliance with treatment (Cuellar, 1988).

The expression "La vida es dura" ("life is hard") is common among many Mexican Americans who suffer unavoidable hardships such as disability within the family. Yet, the general attitude is one of resignation and acceptance since nothing can be done (Smart \& Smart, 1991). Harward (1969) found that, in general, Mexican Americans in the United States are less likely than Anglo Americans to question or berate their fate, but rather accept their state of health, good or bad, without thought of doing anything to change it.

The Mexican American Family Role in Health Care and Rehabilitation

The family is very important in the Mexican American culture and plays a very crucial role in the rehabilitation process and outcome (Smart \& Smart, 
1991). However, it must be noted that situational factors may play a large role in the life of the family and in their decisions for care for their disabled family member. Such factors must be taken into account in order to carry out a correct and thorough assessment (Anderson, 1989). According to Cuellar (1988), it is important for "care providers [to] be ready to incorporate family members in[to] the decision making process, and to consider what is best for the family not just the individual involved" (p. 31). In addition, the disabled/ill person's role within the family should be recognized across his/her lifespan so that treatment can be adapted to respect the traditional age/ gender/ birth hierarchy within the family (Cuellar, 1988).

According to Cruz (1979), the Hispanic family is a very cohesive unit, and "Hispanic families tend to overprotect and paternalize their disabled. Even if a disabled individual wants to learn to be independent and self-sufficient, he [or she] is seldom allowed to do so" (p. 33). In fact, Arnold and Orozco (1987), who studied the family interactions of 44 Mexican American clients of the Texas Division of Rehabilitation, discovered that Mexican American families were less encouraging of assertive behavior and self-sufficiency based on the age or socioeconomic status of the client. Thus, the greater the age and/or socioeconomic status, the more the family would encourage independence or self-sufficiency. According to Rivera (1983), family over protectiveness was found to be particularly true in cases of family members with congenital disabilities. He further reported that children with such disabilities are often kept home from school to be cared for by their concerned families. Such concern, according to Marion (1980), is typical of the Mexican American family, which 
traditionally has the support of an extended family network, and should not be viewed as pathological. Schreiber and Homiak (1981) described the traditional Mexican American family typically as:

a large, close-knit kin group, including both lineal and collateral relatives. Ties beyond the nuclear family are strong and extensive, linking grandparents, aunts, uncles, and cousins in relationships characterized by frequent material and emotional supportive exchanges. This kin network is frequently extended by the institution of "compadrazgo" ("ritual coparenthood") in which "compadres" and "comadres" assume the rights and obligations of relatives. (p.306)

This situation is different from the mainstream Anglo American culture in the United States, in which individuals tend to be part of small nuclear families of parent or parents and children, and stress is placed more on the values of the individual rather than on the family as one cohesive unit (Anderson, 1989). Responsibility for the family is well-defined by social roles in Mexican American culture.

\section{Mexican American Social Roles by Gender}

Rivera (1983) noted the correlation between the well-defined gender roles of men and women in the Mexican American culture and acceptance of disability. In general, Rivera (1983) reported that Mexican American men have been taught that it is their responsibility to provide for the welfare of their family, and women, that it is their responsibility to be good homemakers. Thus, the Mexican American man with a disability may have his image and role as 
"provider" destroyed. According to Schreiber and Homiak (1981), the Mexican American male with a disability, in his experience of facing a diminished role, may try to make up for his perceived "weakness" in the eyes of family members by discontinuing treatment at the first sign of symptom relief to resume normal work activities. The male with a disability may also perceive the admission of needing help as a sign of weakness and a threat to his male image and, thus, may continue unsuccessfully to try to work (Rivera, 1983).

Mexican American Community and Physical Disability

Smart and Smart (1991) have suggested that the Hispanic population in general, including Mexican Americans, is over represented in physically demanding jobs and have lower education levels. They go on to report that these factors play a major role in the number of resources available to members of the community who have a disability, and that these individuals might then accept disability differently than those who have a greater number of opportunities and options for support available to them (Smart \& Smart, 1991). In addition, Smart and Smart (1991) pointed out that for those individuals of Mexican American origin who have earned their living in physically demanding jobs and have limited English proficiency, a physical disability might severely limit employment and training opportunities and may mean more than simply a physical loss.

Theoretical Perspective and Conceptual Framework The Occupational Behavior frame of reference as developed by Reilly (1974) was used to guide this research. According to this frame of reference, people with disabilities are impaired in their ability to perform tasks for their life 
roles at a satisfactory level of mastery, and thus fail to achieve an inborn need (Reilly, 1974). Also, this theory suggests that to adapt successfully and promote life satisfaction, engagement in occupation (activity) is essential (Reilly, 1974). Matsutsuyu (as cited in Hopkins \& Smith, 1988), in exploring the holistic developmental approach of the Occupational Behavior frame of reference, proposed that occupational therapy "shift its initial perspective of patients from diagnostic labels to those of occupational roles [such as] worker, student, housewife, retiree, preschooler" (p. 370). In so doing, this theory, according to Shannon (as cited in Hopkins \& Smith, 1988), transcends the concern of a solely biomedical approach to address the greater concerns related to the performance of roles. Thus, during treatment, attention would be directed, not just toward the biomedical needs of the patient, but toward the disorganized behaviors produced by the patient's illness or disability. Since the merit of the current study is based on the gathering of information of valued roles according to the Mexican American perspective, the Occupational Behavior frame of reference assists in the task of determining the importance of various activities in relation to such valued roles, and can be used to assist occupational therapists in prescribing more sensitive, meaningful treatment strategies for patients of Mexican American descent. This frame of reference relates more specifically to people with disabilities who are not always able to continue to perform the daily social roles they value or that are valued most by the culture/society in which he/she normally functions. The person's disability, according to this frame of reference, will likely be viewed as a role disruption. In order to restore function, it becomes the occupational therapist's task to 
determine ways of adapting daily activities so that the person can resume performance of those roles that are most important to him/her in his/her culture and to structure activities in treatment toward this goal.

\section{Stearn's Research}

The main ideas established in Stearns' (1988) study are:

(1) Many of the cultural beliefs and traditional health care practices of the Vietnamese culture were found to be different from those of the majority of Americans and often misunderstood in Anglo American society. (Misinterpretations/conflicts between belief systems can contribute to communication difficulties between the therapist/health care professional and the patient.)

(2) The social roles held by Vietnamese people tend to emphasize interdependence within the family, the primary social unit of the Vietnamese culture. This varies from the independence promoted and valued by most Anglo Americans.

(3) " $[R]$ ole disruption may occur with the relocation of [Vietnamese] refugee families, due to the new demands of life in the United States...[and] distress in the family [can] result from consideration of alternate roles as [they] are exposed to western ways in [America]" (p.23).

(4)Culturally sensitive approaches to treatment that can result in increased compliance among patients should be advocated.

(5) The Occupational Behavior frame of reference was useful in guiding her research as it stressed "the importance of social roles in assigning value to activities that support those roles" (p.23). 


\section{Summary}

The emphasis on social roles in this study demonstrates that the Mexican American population, in general, accentuates interdependence of its members within the family and community, and that Mexican American people with disabilities rely heavily on their extended family for support. In contrast, the majority of mainstream Anglo Americans stress independence within a small nuclear family structure. Also, the literature shows that the Mexican American male's status as "provider" can be damaged severely when disability affects his life, and that a diminished image can profoundly affect a person's daily work and social activities, as well as attitudes toward disability in general. In addition, the occupational behavior frame of reference guiding this research emphasizes the importance of social roles in assigning value to the activities of daily living which support those roles.

The literature also suggested that many of the cultural and religious beliefs, as well as traditional health care practices of people of Mexican American origin, are different from those of the mainstream Anglo American majority, and are therefore often misunderstood (Kraft,1979). In addition, the literature suggests that there is a profound unmet need among the Mexican American community for rehabilitation services that give sufficient consideration to cultural factors and that this need is supported by high numbers of Mexican American people within the general population, coupled with their over representation in physically demanding and dangerous employment positions (Angel, 1984; Kapur, 1986; McLemore \& Romo, 1985). However, despite their needs for rehabilitative services, it has been shown that the Mexican American 
population experiences limited insurance coverage (Smart, 1993), low referral rates and high drop-out rates once deemed eligible for rehabilitative services (Linsky, Arnold \& Hancock, 1983; Rivera, 1983; Suazo, 1986). Given such knowledge, one must employ the consideration of cultural factors with greater sensitivity and decrease misunderstandings that can be the basis of decreased patient compliance with treatment.

For occupational therapists, increased awareness and sensitivity toward cultural issues can help to clarify the meaning and importance of particular daily activities to the lives of patients of any ethnic origin served, and can thereby lead to better patient care and compliance. 


\section{CHAPTER THREE}

\section{RESEARCH DESIGN AND METHODOLOGY}

In informal telephone interview sessions with occupational therapists at three Santa Clara County treatment settings, the challenge to become more culturally sensitive was expressed. The therapists interviewed (whose names will be kept anonymous) shared that they frequently experienced some degree of frustration when working with Mexican American patients. Aside from stating that a language barrier was a problem, these therapists expressed that their frustrations stemmed from lack of understanding of the culture of their patients, and that research in this area might help in the process of developing better rapport with and treatment strategies for patients of Mexican American descent.

The purpose for this study was to investigate the perspectives of people of Mexican American origin on issues of independence/dependence of people with disabilities within the home and community. Further, the role expectations for members of the Mexican American community at different ages across the lifespan were explored to help determine the meaning and value of various Activities of Daily Living. Survey methodology was used in this investigation.

\section{Survey Methodology}

The rationale for the use of a survey design was to reach the largest number of of Mexican American perspective respondents with the least amount of expenditure in the way of money, recruitment, travel and time. Since a survey format was the means by which Stearns (1988) gathered her data, and since this study is based upon that of Stearns (1988), this method was used to maintain continuity. 


\section{Instrument Development}

With the need for more research of cultural issues in health care, including those pertaining to people of Mexican American descent, a survey questionnaire was adapted for people of Mexican American origin based on the questionnaire used in the Stearns (1988) thesis. The questionnaire (refer to Appendix A) consisted of 20 questions. The format used both closed and open ended questions to allow for explanations which could promote further understanding about the Mexican American culture. The questions covered the following areas: (a) demographics, (b) perspectives towards independence of people with disabilities within the family environment, (c) social roles within the Mexican American community, and (d) concluding questions about disability which focus on the participants' perceptions of the goal of rehabilitation and anticipated use of community resources.

The participants' viewpoints were sought through questions posed about hypothetical families that contained a family member who had a disability. Participants were required to answer the questions posed from the perspective of a person with a disability within a Mexican American family. Participants were also asked to assume the role of a parent of a child with a disability, then the role of a child of a parent with a disability and to answer corresponding hypothetical questions.

Advice for a sound, culturally sensitive instrument was taken from the recommendations of Stearns' (1988) study. Additional advice for a sound and reliable version of this questionnaire for use with a Mexican American population was sought from various Mexican American community members 
who reviewed the preliminary survey instrument.

As per the recommendations from Stearns (1988), hypothetical situations were used since the situations posed in the questionnaire were thought to be less offensive and more tactful. Stearns also suggested that such an approach would probably increase the number of people who were willing to participate in the study.

Unlike Stearns' (1988) study, subjects sought for this investigation were literate in the English language. Therefore, no translation into Spanish via a translator was necessary. The omission of a Spanish speaking sample and Spanish version of the questionnaire was primarily due to budgetary and sample recruiting constraints. However, this omission also proved to further simplify the data analysis process and thereby assured better reliability and validity of the data collected.

\section{Subjects and Sampling}

The subjects for this study were recruited via a convenience sampling technique, gathering subjects of Mexican American descent through various Latino clubs and departments on the San Jose State University campus. Recruitment of subjects, using this technique, was based on the following criteria: (a) participants were self-identified as Mexican American or as American of Mexican origin; (b) participants had to be able to read and write English; and (c) participants had to reside within the vicinity of the Santa Clara County in the state of California. The subjects who participated in this study demonstrated their consent for participation by their return of a completed questionnaire to the researcher. No signature was required, thus, the findings 
were not able to be traced to any participant, and they remained anonymous.

Contact people at San Jose State University's Mexican American

Studies program and Latino clubs on San Jose State University's campus were sought to facilitate access to the sample population for this study. A return rate of at least 20 usable questionnaires was anticipated and 25 were actually obtained. Further recruiting of subjects was not needed since the subject quota did not fall short of its goal of at least 20 usable questionnaires.

\section{Data Collection}

The data for this study were collected in classrooms and/or offices at San Jose State University via this researcher's personal administration of the questionnaire to self-reported Mexican American students and faculty who were agreeable to being participants. Subjects who were concerned about the estimated $\mathbf{2 0}$ minutes it took to fill out the survey or who had other financial concerns were given a small token honorarium of $\$ 2$ (the cost of parking for 1 day at San Jose State University) for their time and willingness. This method of administration was chosen following a difficult period locating willing participants. It was believed that, under the circumstances, this would be the best method to obtain a workable return rate of at least 20 questionnaires. However, 25 questionnaires was the final usable return. This number of subjects was slightly more than the 20 subjects received for the Stearns (1988) study.

\section{Data Analysis}

Based on the combined quantitative and qualitative nature of the data, the strictly English version of the questionnaire, and the number of participants, 
the analysis of the data did not require sophisticated statistical methods.

Instead, frequency tables were prepared by the researcher. Since the data were collected from people of Mexican American origin residing in the vicinity of Santa Clara County, it is not generalizable to the larger population of Mexican Americans residing in the United States. 


\section{CHAPTER FOUR \\ DATA AND RESULTS}

The results of this study are based on the responses to a survey questionnaire administered to $\mathbf{2 5}$ self-identified Mexican American subjects who live in Santa Clara County, California. The questionnaire was designed to investigate the participants' perspectives on independence and role fulfillment of people with disabilities. Those items which the participants left incomplete on the questionnaires were deleted from the total available number of responses for that particular question. Such deletions are reflected in the overall statistics for this study. Both the quantitative and qualitative results to each of the survey questions are reported in the order as they were given to the subjects.

Frequency tables are provided to demonstrate the overall distribution and percentage of responses to questions and used to answer research questions.

\section{Demographic Data}

\section{Age and Gender}

The 25 self-identified Mexican American subjects who returned questionnaires ranged in age from 20 to 59 years, with $23(92 \%)$ of the respondents in the 20 to 39 year old age bracket. Of the 25 subjects who participated in this study, there were $13(52 \%)$ males and $12(48 \%)$ females.

\section{Residency Status}

Seventeen (68\%) of the 25 participants have lived in the United States since birth, seven (28\%) have lived in the United States for up to 19 years, and one person (4\%) has lived in the United States for 20 to 39 years. None of the participants reported living in the United States longer than 39 years. 


\section{Present Level of Education}

All of the subjects who participated in this study reported they had graduated from high school. All of the subjects were literate in English (were able to read, write, and speak English fluently). Of the 25 subjects, 16 (64\%) reported that they were current matriculating students in a Bachelors degree program, four (16\%) reported that they had graduated with either a Bachelor of Science or Bachelor of Arts degree, two (8\%) reported that they were currently graduate students earning a Master of Arts or Master of Science degree, two (8\%) reported to have some college education, and one (4\%) reported that she had earned a Doctorate degree (Ph.D).

\section{Religion}

Religious associations among the study's participants showed the majority to be Roman Catholic ( $\underline{n}=17,68 \%)$. Others reported to be Seventh Day Adventist ( $n=1,4 \%)$, Pentecostal $(n=1,4 \%)$, Non-denominational Christian $(\underline{n}=1,4 \%)$, Mormon/ Church of Jesus Christ of Latter Day Saints $(\underline{n}=1,4 \%)$, and not currently associated with any particular religious group $(n=4,16 \%)$.

\section{Perspectives on Disability as a Person with a Disability}

In order to answer the questions presented in this section, the participants were instructed to respond as if they knew someone of their same gender and age group who had a severe disability.

\section{Independence in Activities of Daily Living}

In this subsection, subjects were given a choice of ten options and an opportunity to write-in their own response (under the option "other") if they had 
an additional answer that varied from the options provided. In this way subjects were given the opportunity to express their perspectives on disability as if they were a person who had a severe disability.

Given a list of various activities of daily living, the participants selected the following activities as most desired to be performed independently by a person with a disability: toileting ( $(n=21,84 \%)$, eating $(\underline{n}=18,72 \%)$, bathing $(\underline{n}=16,64 \%)$, dressing $(n=9,36 \%)$, operating a car or wheelchair $(\underline{n}=4,16 \%)$ and grooming $(\underline{n}=4,16 \%)$, meal preparation $(\underline{n}=3,12 \%)$, and housekeeping $(\underline{n}=2,8 \%)$. None of the participants thought the activities of child care $(\underline{n}=0)$ or house maintenance $(n=0)$ would be most desired to be performed independently by a person with a disability (see Table 1).

The participants selected the following activities of daily living as those for which they perceived a person with a disability would be most willing to accept assistance with: meal preparation ( $\underline{n}=22,88 \%)$, housekeeping $(\underline{n}=19$, $76 \%)$, house maintenance $(\underline{n}=18,72 \%)$, child care $(\underline{n}=7,28 \%)$, grooming $(\underline{n}=3$, $12 \%)$, operating a car or wheelchair $(\underline{n}=3,12 \%)$, bathing $(\underline{n}=2,8 \%)$, and dressing $(n=1,4 \%)$. None of the participants believed that a person with a disability would be as willing to accept assistance with toileting $(\underline{n}=0)$ or eating $(\underline{n}=0)$ (see Table 2).

The participants of this study reported the following responses to the activities with which a person with a disability would feel most obligated to accept assistance: meal preparation $(\underline{n}=8,32 \%)$ and toileting $(\underline{n}=8,32 \%)$, bathing ( $n=7,28 \%)$ and house maintenance $(\underline{n}=7,28 \%)$, as well as housekeeping ( $\underline{n}=6,24 \%)$, with eating $(\underline{n}=5,20 \%)$, child care $(\underline{n}=4,16 \%)$ and 
Table 1

Activities of Daily Living (ADL) Most Desired for Independence by a Person with Disability ( $\mathrm{N}=25)$ :

\begin{tabular}{lcc}
\hline ADL & Frequency & Percentage \\
\hline Toileting & 21 & $84 \%$ \\
Eating & 18 & $72 \%$ \\
Bathing & 16 & $64 \%$ \\
Dressing & 9 & $36 \%$ \\
Operating a Car or Wheelchair & 4 & $16 \%$ \\
Grooming & 4 & $16 \%$ \\
Meal Preparation & 3 & $12 \%$ \\
Housekeeping & 2 & $8 \%$ \\
Child Care & 0 & $0 \%$ \\
House Maintenance & 0 & $0 \%$ \\
Other & 0 & $0 \%$ \\
\end{tabular}


Table 2

Acceptance of Assistance in Activities of Daily Living (ADL) by a Person with Disability $(\mathrm{N}=25)$ :

\begin{tabular}{lcc} 
ADL & Frequency & Percentage \\
\hline Meal Preparation & 22 & $88 \%$ \\
Housekeeping & 19 & $76 \%$ \\
House Maintenance & 18 & $72 \%$ \\
Child care & 7 & $28 \%$ \\
Grooming & 3 & $12 \%$ \\
Operating a Car or Wheelchair & 3 & $12 \%$ \\
Bathing & 2 & $8 \%$ \\
Dressing & 1 & $4 \%$ \\
Toileting & 0 & $0 \%$ \\
Eating & 0 & $0 \%$ \\
Other & 0 & $0 \%$ \\
& & \\
\hline
\end{tabular}


operating a car or wheelchair $(\underline{n}=4,16 \%)$, dressing $(\underline{n}=3,12 \%)$, and grooming ( $n=2,8 \%$ ). Six or $24 \%$ of the subjects reported no feelings of obligation to accept any assistance. Two of the participants chose the response labeled "other" (8\%). Of these, one reported that she believed a person with a disability would feel obligated to receive assistance with driving in order to get to doctor's appointments. The other person simply indicated that she did not know (see Table 3).

\section{Preference Regarding Familial Relationship} and Gender of Caretakers and Therapists

When participants were asked who they would prefer to assist a person with a disability of their same gender and age group, the majority responded that they would prefer the caretaker for self-care activities (grooming, eating, dressing, bathing, toileting) to be a female in the family ( $n=14,56 \%)$. Of these respondents, seven were male (53.8\% of all male respondents) and seven were female ( $58.3 \%$ of all female respondents).

Nine (36\% of the total sample) reported that they would prefer a female attendant outside the family. Of those who gave this response, four were male ( $44.4 \%$ of all male participants) and five were female (55.5\% of all female participants). Two male participants ( $8 \%$ of the total sample and $15.4 \%$ of all male participants) and none of the female participants reported preference for a male in the family to assist with self-care activities. None of the participants indicated that they would prefer a male attendant outside the family to help with self-care needs nor were there any other write-in responses (see Table 4).

If training in self-care activities by a therapist was a requirement, the 
Table 3

Feelings of Obligation by a Person with a Disability to Accept Assistance in Activities of Daily Living (ADL) ( $N=25)$ :

\begin{tabular}{lll}
\hline ADL & Frequency & Percentage \\
\hline Meal Preparation & 8 & $32 \%$ \\
Toileting & 8 & $32 \%$ \\
Bathing & 7 & $28 \%$ \\
House Maintenance & 7 & $28 \%$ \\
Housekeeping & 6 & $24 \%$ \\
Do Not Feel Obligated & 6 & $24 \%$ \\
Eating & 5 & $20 \%$ \\
Child Care & 4 & $16 \%$ \\
Operating a Car or Wheelchair & 4 & $16 \%$ \\
Dressing & 3 & $12 \%$ \\
Grooming & 2 & $8 \%$ \\
Other & 2 & $8 \%$ \\
\hline
\end{tabular}


Table 4

Preferred Familial Relationship and Gender of Caretakers for a Person with Disability ( $\mathrm{N}=25)$ :

\begin{tabular}{lll}
\hline Preferred Caretaker & Frequency & Percentage \\
\hline Female in the Family & 7 Males & $53.9 \%$ \\
Female Attendant Outside Family & 7 Females & $58.3 \%$ \\
Male in the Family & 4 Males & $30.8 \%$ \\
& 5 Females & $41.7 \%$ \\
Male Attendant Outside Family & 2 Males & $15.4 \%$ \\
& 0 Females & $0.0 \%$ \\
Other & 0 Males & $0.0 \%$ \\
& 0 Females & $0.0 \%$ \\
& 0 Males & $0.0 \%$ \\
\hline
\end{tabular}


majority of the participants ( $\underline{n}=16,64 \%$ of the total sample) reported that a person with a disability would have no preference for gender of their therapists. Of the participants who responded in this way, ten were male $(76.9 \%$ of all male respondents) and six were female (50\% of all female respondents). Eight of the participants (32\% of the total sample) preferred a female therapist over a male. Five of those respondents were female ( $41.7 \%$ of all the female participants) and three were male (23.1\% of all the male participants). Only one participant, a female ( $4 \%$ of the total population, and $8.3 \%$ of all female participants), indicated the preference for a male therapist (see Table 5).

\section{Perspectives on Disability as a Parent}

In answering the questions presented in this section, the participants were asked to imagine that they knew a parent with a child who had a severe disability.

\section{Parental Assistance for a Child with a Disability}

When the participants were asked their expectations as a parent who needed help for their child who had a disability and who needed help with certain activities of daily living, 23 ( $92 \%$ of the total sample) indicated that they believed the parent would feel obligated to assist the child. Of these, 13 were male $(100 \%$ of all the male participants) and ten were female $(83.3 \%$ of all the female participants). Two of the participants ( $8 \%$ of the total sample) were undecided as to whether the parent would feel obligated to assist the child. Of those who responded in this way, two were female $(16.6 \%$ of all female participants) and none were male. None of the participants indicated they expected the parents would not help their child. 
Table 5

Preferred Gender of Therapist for Self-Care Activities Training ( $\mathrm{N}=25)$ :

\begin{tabular}{clc}
\hline Preferred Gender & Frequency & Percentage \\
\hline \multirow{2}{*}{ No Preference } & 10 Males & $76.9 \%$ \\
& 6 Females & $50.0 \%$ \\
Female & 3 males & $23.1 \%$ \\
& 5 Females & $41.7 \%$ \\
Male & 0 Males & $0.0 \%$ \\
& 1 Female & $8.3 \%$ \\
\hline
\end{tabular}


Of the male participants, nine ( $36 \%$ of the total sample) gave explanations for the answers they selected. The most common explanation for the affirmative answer by the male participants was that "it is the responsibility of the parents to take care of their children and family any way possible" $(\underline{n}=8$, $61.5 \%$ of all the male respondents). One male participant ( $7.6 \%$ of all male respondents) commented that he felt the parent should "only help with the necessities and then help the child to do what he/she can do on their own". None of the male participants answered "no" or "not sure" for this question.

Of the ten female respondents who answered in the affirmative the most common explanation tended to be that it "is the job and role of the parent to take care of their child, and so they would" ( $\underline{n}=7,58.3 \%$ of all female respondents). The responses of the other three females who answered in the affirmative varied. One ( $8.3 \%$ of all female respondents) commented that "the parents would help because they are more experienced, knowledgeable, and are the main support system for the child and the family." Two others ( $16.6 \%$ of all female respondents) responded that they were unable to explain why the parents would help the child with certain activities but that "they must offer assistance." Two of female participants ( $16.6 \%$ of all female respondents) who indicated they were "not sure" whether the parents would assist their child with certain activities of daily living did not explain their answers.

If the parents did feel obligated to help their child with a disability, the following list of activities were considered "most important" by the participants for which to lend assistance: toileting ( $\underline{n}=16$; males $=9$, females $=7 ; 64 \%$ of the total sample, $69.2 \%$ of all male respondents, $58.3 \%$ of all female respondents), 
bathing ( $\mathrm{n}=16$; males $=9$, females $=7 ; 64 \%$ of the total sample, $69.2 \%$ of all male respondents, $58.3 \%$ of all female respondents), eating ( $\underline{n}=14$; males $=8$, females $=6 ; 56 \%$ of the total sample, $61.5 \%$ of all male respondents, $50 \%$ of all female respondents), meal preparation ( $\underline{n}=9 ;$ males $=5$, females $=4 ; 36 \%$ of the total sample, $38.5 \%$ of all male respondents, $33.3 \%$ of all female respondents), dressing ( $n=8$; males $=5$, females $=3 ; 32 \%$ of the total sample, $38.5 \%$ of all male respondents, $25 \%$ of all female respondents), child care $(\underline{n}=7$; males $=4$, females $=3 ; 28 \%$ of the total sample, $30.8 \%$ of all male respondents, $25 \%$ of all female respondents), grooming ( $\underline{n}=6$; males $=3$, females $=3 ; 24 \%$ of the total sample, $23.1 \%$ of all male respondents, $25 \%$ of all female respondents), operating a wheelchair ( $\mathrm{n}=5$; males $=5$, females $=0 ; 20 \%$ of the total sample, $38.5 \%$ of all male respondents, $0 \%$ of all female respondents), house maintenance ( $\underline{n}=4$; males $=2$, females $=2 ; 16 \%$ of the total sample, $15.4 \%$ of all male respondents, $16.7 \%$ of all female respondents), housekeeping ( $n=4$; males $=3$, females $=1 ; 16 \%$ of the total sample, $23.1 \%$ of all male respondents, $8.3 \%$ of all female respondents), and other responses written in ( $\mathrm{n}=2$; males $=2$, females $=0,8 \%$ of the total sample population, $15.4 \%$ of all male respondents, $0 \%$ of all female respondents) in which participants reported that they thought the parents would feel obligated to help their child with all of the activities listed (see Table 6).

In the instance that the child with a disability did not want help with selfcare activities, most of the participants indicated they expected that the parents would allow the child to do these activities independently ( $\mathrm{n}=12,48 \%$ of the total sample). Of those who answered in the affirmative, four were male 
Table 6

Parental Assistance with Activities of Daily Living (ADL) for a Child with a Disability $(\mathrm{N}=25)$ :

\begin{tabular}{lcc}
\hline ADL & Frequency & Percentage \\
\hline Toileting & 16 Total & $64.0 \%$ \\
& 9 Males & $69.2 \%$ \\
Bathing & 7 Females & $58.3 \%$ \\
& 16 Total & $64.0 \%$ \\
Eating & 9 Males & $69.2 \%$ \\
& 7 Females & $58.3 \%$ \\
Meal Preparation & 14 Total & $56.0 \%$ \\
& 8 Males & $61.5 \%$ \\
Dressing & 6 Females & $50.0 \%$ \\
& 9 Total & $36.0 \%$ \\
Child care & 5 Males & $38.5 \%$ \\
& 4 Females & $33.3 \%$ \\
Grooming & 8 Total & $32.0 \%$ \\
& 5 Males & $38.5 \%$ \\
Operating a Car or Wheelchair & 3 Females & $25.0 \%$ \\
& 7 Total & $28.0 \%$ \\
House Maintenance & 4 Males & $30.8 \%$ \\
& 3 Females & $25.0 \%$ \\
Housekeeping & 6 Total & $24.0 \%$ \\
& 3 Males & $23.1 \%$ \\
& 3 Females & $25.0 \%$ \\
Other & 5 Total & $20.0 \%$ \\
& 5 Males & $38.5 \%$ \\
& 4 Total & $16.0 \%$ \\
& 2 Males & $15.4 \%$ \\
& 2 Females & $16.7 \%$ \\
& 4 Total & $16.0 \%$ \\
& 3 Males & $23.1 \%$ \\
& 1 Female & $8.3 \%$ \\
& 2 Total & $8.0 \%$ \\
& 2 Males & $15.4 \%$ \\
\hline
\end{tabular}


(30.8\% of all male respondents) and eight were female $(66.6 \%$ of all female respondents). Seven of the participants ( $28 \%$ of the total sample, $5=$ males or $38.5 \%$ of all male respondents, $2=$ females or $16.7 \%$ of all female respondents) indicated that they were not sure if the parents would let the child perform selfcare activities independently. There were six participants ( $24 \%$ of the total sample) who reported that they believed the parents would not allow their child to perform self-care activities without help, even if the child did not want assistance. Of those who responded in this way, four were male (30.8\% of all male respondents) and two were female (16.7\% of all female respondents) (see Table 7).

The following were some of the most common explanations given by those who believed that the parents would allow their child with a disability to perform independently. Two participants, 1 male and 1 female, stated that only if the child is capable, then the parents should let him/her do what he/she can independently. Other responses included letting the child try to do the activities on his/her own so that he/she can find out how difficult it really is and how much he/she needs the parent's help ( $n=2$, male=1, female $=1$ ), letting the child do the activities independently "so that the child would feel better about him/herself" ( $n=1$ female), and "because the parents would want to make the child as comfortable as possible" ( $\underline{n}=1$ female).

The following are some of explanations by the six respondents who indicated their belief that the parents would not allow the child to perform activities of daily living independently, even if the child did not want assistance: two males made the point that Mexican American parents would tend to hold 
Table 7

Expectation for Independent Performance in Activities of Daily Living (ADL) for a Child with a Disability $(\mathrm{N}=25)$ :

\begin{tabular}{llr}
\hline Expectation & Frequency & Percentage \\
\hline Yes & 12 Total & \\
& 4 Males & $48.0 \%$ \\
& 8 Females & $30.8 \%$ \\
No & 6 Total & $66.7 \%$ \\
& 4 Males & $24.0 \%$ \\
& 2 Females & $30.8 \%$ \\
Not Sure & 7 Total & $16.7 \%$ \\
& 5 Males & $28.0 \%$ \\
& 2 Females & $38.5 \%$ \\
\hline
\end{tabular}


onto the belief that they know what is best for their child and "would take control of the situation", one male indicated that "the child may not be capable", and another that it would not be right since "the parent is responsible for the child", one female said that "it is expected that the parents and other family members will help" and another said that "the parents should help because if they did not then they would probably feel they were failing as a parent."

Those who responded that they were not sure if the parents should help or not gave the following explanations: three males and one female indicated that allowing independence "would depend on the severity of the disability", and two other males indicated that "the parents would be obligated to help if the child was incapable" of doing the activities on his own or "if the child could harm himself doing the activities on his own."

\section{The Most Influential Person in the Decision of}

\section{Lending Assistance to a Child with a Disability}

When asked who would be the most influential person in the parents' decision to help or not to help their child with activities of daily living, the participants indicated the following people: the disabled child $(n=12$; males $=6$, females $=6 ; 48 \%$ of the total sample, $46.2 \%$ of all the males, $50 \%$ of all the females), the therapist working with the child on self-care activities ( $\underline{n}=10$; males $=4$, females $=6 ; 40 \%$ of the total sample, $30.8 \%$ of all the males, $50 \%$ of all the females), the oldest family member regardless of $\operatorname{sex}(\underline{n}=9$; males $=4$, females $=5 ; 36 \%$ of the total sample, $30.8 \%$ of all the males, $41.7 \%$ of all the females), the attending western medical doctor ( $n=7$; males $=6$, females $=1 ; 28 \%$ of the total sample, $46.2 \%$ of all the males, $8.3 \%$ of all the females), the 
attending traditional Hispanic doctor/healer/curandero $(\underline{n}=4 ;$ males $=1$, females $=3 ; 16 \%$ of the total sample, $7.7 \%$ of all the males, $25 \%$ of all the females), a religious leader ( $n=4$; males $=2$, females $=2 ; 16 \%$ of the total sample, $15.4 \%$ of all the males, $16.7 \%$ of all the females), the oldest male family member ( $\underline{n}=2$, males $=2$, females $=0 ; 8 \%$ of the total sample, $15.4 \%$ of all the males, $0 \%$ of all the females), and other write-in responses ( $n=2$; male $=1$, female $=1 ; 8 \%$ of the total sample, $7.7 \%$ of all the males, $8.3 \%$ of all the females) being "a western Hispanic doctor" ( $\underline{n}=1)$ and "the oldest female family member" $(\underline{n}=1)$ (see Table 8).

\section{Perspectives on Disability as a Son or Daughter}

In answering the questions posed in this section, the participants were instructed to imagine they knew a person of their same gender and age group who had a parent with a severe disability.

\section{Child's Assistance of a Parent with a Disability}

All of the participants in this study indicated their belief that the son or daughter of a parent with a severe disability would feel the need to help the parent with certain activities of daily living ( $\underline{n}=25,100 \%$ of the total sample). Of those who responded in this way, 13 were male (100\% of the male sample) and 12 were female $(100 \%$ of the female sample).

Many of the explanations provided for the affirmative answer indicated that the child of a parent with a disability would assist their parent because it was their moral and ethical "obligation" ( $\underline{n}=7 ; 28 \%$ of the total sample, 4 males or $30.8 \%$ of the male sample and 3 females or $25 \%$ of the female sample) and/or "responsibility" ( $\underline{n}=6 ; 24 \%$ of the total sample, 3 males or $23.1 \%$ of the 
Table 8

The Most Influential Person in the Decision to Lend Assistance to a Child with a Disability ( $\mathrm{N}=25)$ :

Person

Frequency

Percentage

The Child with a Disability

12 Total

$48.0 \%$

6 Males

$46.2 \%$

6 Females

$50.0 \%$

The Therapist Working with the Child on Self-care Activities

10 Total

$40.0 \%$

4 Males

$30.8 \%$

6 Females

$50.0 \%$

The Oldest Family Member

Regardless of Gender

9 Total

$36.0 \%$

4 Males

$30.0 . \%$

5 Females

$41.7 \%$

Western Medical Doctor

7 Total

$28.0 \%$

6 Males

$46.2 \%$

1 Female

$8.3 \%$

Traditional Mexican American Healer

4 Total

$16.0 \%$

1 Male

$7.7 \%$

3 Females

$25.0 \%$

Religious Leader

4 Total

$16.0 \%$

2 Males

$15.4 \%$

2 Females

$16.7 \%$

The Oldest Male Family Member

2 Total

$8.0 \%$

2 Males

$15.4 \%$

Other

$\begin{array}{ll}2 \text { Total } & 8.0 \% \\ 1 \text { Male } & 7.7 \% \\ 1 \text { Female } & 8.3 \%\end{array}$


male sample, and 3 females or $25 \%$ of the female sample) or that "it is the expectation for the child to take care of the parents" who raised him/her ( $\underline{n}=3$; $12 \%$ of the total sample, 1 male or $7.7 \%$ of the male sample, and 2 females or $16.7 \%$ of the female sample). Similar explanations given included the belief that "Mexican Americans do not believe in putting their parents into convalescent hospitals" ( $n=1$ male, $4 \%$ of the total sample and $7.7 \%$ of the male sample), and the belief in the "reciprocation of help" since the parents took care of the child growing up ( $n=6,24 \%$ of the total population; 4 males or $30.8 \%$ of the male sample and 2 females or $16.7 \%$ of the female sample). Other participants expressed that "it is the right thing to do" ( $n=2$ females, $8 \%$ of the total sample and $16.7 \%$ of the female sample).

The following are the activities the participants believed to be most important for which a son/daughter with a parent with a disability would lend assistance: meal preparation ( $n=19 ; 76 \%$ of the total sample, 12 males or $92.3 \%$ of the male sample, 7 females or $58.3 \%$ of the female sample), eating ( $n=15 ; 60 \%$ of the total sample, 8 males or $61.5 \%$ of the male sample and 7 females or $58.3 \%$ of the female sample), house maintenance ( $\underline{n}=13$ or $52 \%$ of the total population, 8 males or $61.5 \%$ of the male sample and 5 females or $41.7 \%$ of the female sample), toileting ( $n=10$ or $40 \%$ of the total sample, 4 males or $30.8 \%$ of the male sample and 6 females or $50 \%$ of the female sample), bathing ( $n=7$ or $28 \%$ of the total sample, 3 males or $23.1 \%$ of the male sample and 4 females or $33.3 \%$ of the female sample), housekeeping ( $n=7$ or $28 \%$ of the total sample, 5 males or $38.5 \%$ of the male sample and 2 females or $16.7 \%$ of the female sample), dressing ( $\underline{n}=6 ; 24 \%$ of the total sample, 4 males or 
$30.8 \%$ of the male sample and 2 females or $16.7 \%$ of the female sample), grooming ( $\underline{n}=6 ; 24 \%$ of the total sample, 3 males or $23.1 \%$ of the male sample and 3 females $25 \%$ of the female sample), operating a wheelchair ( $\underline{n}=5 ; 20 \%$ of the total sample, 4 males or $30.8 \%$ of the male sample and 1 female or $8.3 \%$ of the female sample), child care ( $n=2 ; 8 \%$ of the total sample, 2 males or $15.4 \%$ of the male sample and 0 females), and two who chose the "other" response ( $8 \%$ of the total sample with 2 males or $15.4 \%$ of the male sample and 0 females) and indicated that "all of the above" listed activities would be important for a son or daughter to lend assistance (see Table 9).

Even if the parent with a disability did not want help with activities of daily living, nine of the participants (36\% of the total sample, 5 males or $38.5 \%$ of the male sample and 4 females or $33.3 \%$ of the female sample) indicated their expectation that the son or daughter would be unsure of a decision to allow their father or mother with a disability to perform these activities independently. Eight of the participants (32\% of the total sample, 4 males or $30.8 \%$ of the male sample and 4 females or $33.3 \%$ of the female sample) expected that the son or daughter would allow the parent independence if he/she wanted it. Seven (28\% of the total sample, 3 males or $23.1 \%$ of the male sample and 4 females or $33.3 \%$ of the female sample) indicated their belief that the son or daughter would not allow the parent to do these activities independently, even if the parent wanted to (see Table 10).

The most common explanation given for the "unsure" answer was that "it would depend on the type of disability and the severity" ( $\underline{n}=4$ or $16 \%$ of the total sample; 2 males or $15.4 \%$ of the male sample and 2 females or $16.7 \%$ of the 


\section{Table 9}

Child's Assistance with Activities of Daily Living (ADL) for a Parent with a Disability $(\mathrm{N}=25)$ :

\begin{tabular}{|c|c|c|}
\hline$\overline{\mathrm{ADL}}$ & Frequency & Percentage \\
\hline \multirow[t]{2}{*}{ Meal Preparation } & 19 Total & $76.0 \%$ \\
\hline & $\begin{array}{l}12 \text { Males } \\
7 \text { Females }\end{array}$ & $\begin{array}{l}92.3 \% \\
58.3 \%\end{array}$ \\
\hline \multirow[t]{2}{*}{ Eating } & 15 Total & $60.0 \%$ \\
\hline & $\begin{array}{l}8 \text { Males } \\
7 \text { Females }\end{array}$ & $\begin{array}{l}61.5 \% \\
58.3 \%\end{array}$ \\
\hline \multirow[t]{2}{*}{ House Maintenance } & 13 Total & $52.0 \%$ \\
\hline & $\begin{array}{l}8 \text { Males } \\
5 \text { Females }\end{array}$ & $\begin{array}{l}61.5 \% \\
41.7 \%\end{array}$ \\
\hline \multirow[t]{2}{*}{ Toileting } & 10 Total & $40.0 \%$ \\
\hline & $\begin{array}{l}4 \text { Males } \\
6 \text { Females }\end{array}$ & $\begin{array}{l}30.8 \% \\
50.0 \%\end{array}$ \\
\hline \multirow[t]{2}{*}{ Bathing } & 7 Total & $28.0 \%$ \\
\hline & $\begin{array}{l}3 \text { Males } \\
4 \text { Females }\end{array}$ & $\begin{array}{l}23.1 \% \\
33.3 \%\end{array}$ \\
\hline \multirow[t]{2}{*}{ Housekeeping } & 7 Total & $28.0 \%$ \\
\hline & $\begin{array}{l}5 \text { Males } \\
2 \text { Females }\end{array}$ & $\begin{array}{l}38.5 \% \\
16.7 \%\end{array}$ \\
\hline \multirow[t]{2}{*}{ Dressing } & 6 Total & $24.0 \%$ \\
\hline & 4 Males & $30.8 \%$ \\
\hline \multirow[t]{3}{*}{ Grooming } & $\begin{array}{l}6 \text { Total } \\
6 \text { Temales }\end{array}$ & $\begin{array}{l}10.1 \% \\
24.0 \%\end{array}$ \\
\hline & 3 Males & $23.1 \%$ \\
\hline & 3 Females & $25.0 \%$ \\
\hline \multirow[t]{3}{*}{ Operating a Car or Wheelchair } & 5 Total & $20.0 \%$ \\
\hline & 4 Males & $30.8 \%$ \\
\hline & 1 Female & $8.3 \%$ \\
\hline \multirow{3}{*}{ Child care } & 2 Total & $8.0 \%$ \\
\hline & 2 Males & $15.4 \%$ \\
\hline & 0 Females & $0.0 \%$ \\
\hline \multirow[t]{3}{*}{ Other } & 2 Total & $8.0 \%$ \\
\hline & 2 Males & $15.4 \%$ \\
\hline & 0 Females & $0.0 \%$ \\
\hline
\end{tabular}


Table 10

Expectations by a Child for Activities of Daily Living Performed Independently by a Parent with a Disability $(\mathrm{N}=25)$ :

\begin{tabular}{clr}
\hline Expectation & Frequency & Percentage \\
& & \\
\hline \multirow{2}{*}{ Yes } & 8 Total & $32.0 \%$ \\
& 4 Males & $30.8 \%$ \\
No & 4 Females & $33.3 \%$ \\
& & $28,0 \%$ \\
& 7 Total & $23.1 \%$ \\
Not Sure & 3 Males & $33.3 \%$ \\
& 4 Females & $36.0 \%$ \\
& & $38.5 \%$ \\
& 9 Total & $33.3 \%$ \\
\hline
\end{tabular}


female sample). One male ( $4 \%$ of the total sample and $7.7 \%$ of the male sample) expressed that he was "unsure" because "some parents are so used to doing things for themselves that it would be hard for them to obtain assistance from anyone else." One female (4\% of the total sample and $8.3 \%$ of the female sample) expressed that she was "unsure" since allowing independence for the parent with a disability would "depend on the type of household." Another female ( $4 \%$ of the total sample and $8.3 \%$ of the female sample) said that her indecisiveness depended "on the types of activities the parent actually wanted to be able to do independently."

Three (12\% of the total sample, 2 males or $15.4 \%$ of the male sample and 1 female or $8.3 \%$ of the female sample) of those who responded that they believed the son or daughter would allow the parent to perform activities of daily living independently qualified their belief based on "if the parent was [actually] capable" of performing the activities on his or her own. One male (4\% of the total sample and $7.7 \%$ of the male sample) responded that he believed the son or daughter would allow the parent with a disability to do the activities on his/her own "but it would be very difficult and would probably cause problems if they did". Other female participants gave the following responses: that the son or daughter "would allow the parent to do the best they could by [him/her] self given [the] disability" ( $\underline{n}=1$ female; $4 \%$ of the total sample, $8.3 \%$ of the female sample), that the son or daughter would allow it because "it is important to let the parent feel they can manage for [him/her] self if that is what [the parent] want[s]" ( $\underline{n}=1$ female, $4 \%$ of the total sample, $8.3 \%$ of the female sample), or so that "the parent can then see for [him/her] self what he/she can do" ( $\underline{n}=1$ female, 
$4 \%$ of the total sample, $8.3 \%$ of the female sample).

Of the seven participants who believed that the son or daughter would not allow the parent with a disability to perform self-care activities independently, three (12\% of the total sample, 1 female or $8.3 \%$ of the female sample and 2 males or $15.4 \%$ of the male sample) expressed the obligation and custom for family members to try and help the parents, regardless. One male ( $4 \%$ of the total sample or $7.7 \%$ of the male sample) explained that "as Mexican Americans get older they wivuld rather die than burden their children with having to look after them, but that the children should anyway" because it is expected. Another male ( $4 \%$ of the total sample or $7.7 \%$ of the male sample) expressed that the son or daughter "would need to hire an outside person to help them do the activities." One of the female participants ( $4 \%$ of the total sample and $8.3 \%$ of the female sample) explained that "the parents may not yet realize how big the responsibilities are to do certain activities by them[selves]" and so the son or daughter should help them. Another female ( $4 \%$ of the total sample and $8.3 \%$ of the female sample) defended her answer by writing that "it would be unacceptable to let the parent do these by [him/her] self."

The Most Influential Person in the Decision of Lending Assistance to a Parent with a Disability

Overall, the two most influential people in helping a son or daughter decide whether or not to lend assistance to his/her parent with a disability were the father or mother with a disability $(n=16 ; 64 \%$ of the total sample, 8 males or $61.5 \%$ of the male sample and 8 females or $66.7 \%$ of the female sample) and the attending therapist working with the parent on self-care activities $(\underline{n}=11$ or 
$44 \%$ of the total sample, 5 males or $38.5 \%$ of the male sample and 6 females or $50 \%$ of the female sample). Closely following these choices, ten of the participants ( $40 \%$ of the total sample, 7 males or $53.8 \%$ of the male sample and 3 females or $25 \%$ of the female sample) believed that the oldest family member, regardless of sex, would be the most influential person. Eight of the participants (32\% of the total sample with 6 males or $46.2 \%$ of the male sample and 2 females or $16.7 \%$ of the female sample) reported that it would be the attending western medical doctor. Four of the participants (16\% of the total sample, 1 male or $7.7 \%$ of the male sample and 3 females or $25 \%$ of the female sample) reported that the attending traditional Hispanic healer/doctor/curandero would be the most influential. Only two of the participants ( $8 \%$ of the total sample, 1 male or $7.7 \%$ of the male sample and 1 female or $8.3 \%$ of the female sample) reported that a religious leader would be the most influential for the son or daughter's decision. Finally, only 1 female participant ( $4 \%$ of the total sample, $8.3 \%$ of the female sample) wrote that she believed that the oldest female family member would be the most influential (see Table 11).

\section{Social Roles in Community Life}

In order for the person with a disability to receive the most from the rehabilitation process, it is very important for the therapist working with the patient to understand the type of community environment to which he or she will be returning, and to address the needs of the patient accordingly during treatment planning. Satisfactory performance in carrying out social roles and meeting social expectations are imperative to success in the home and community environments (Stearns, 1988). 
Table 11

The Most Influential Person in the Decision to Lend Assistance to a Parent with

a Disability ( $\mathrm{N}=25)$ :

\begin{tabular}{|c|c|c|}
\hline Person & Frequency & Percentage \\
\hline Parent with a Disability & $\begin{array}{l}16 \text { Total } \\
8 \text { Males } \\
8 \text { Females }\end{array}$ & $\begin{array}{l}64.0 \% \\
61.5 \% \\
66.7 \%\end{array}$ \\
\hline $\begin{array}{l}\text { Therapist Working on } \\
\text { Self-Care Activities }\end{array}$ & $\begin{array}{l}11 \text { Total } \\
5 \text { Males } \\
6 \text { Females }\end{array}$ & $\begin{array}{l}44.0 \% \\
38.5 \% \\
50.0 \%\end{array}$ \\
\hline Oldest Family Member & $\begin{array}{l}10 \text { Total } \\
7 \text { Males } \\
3 \text { Females }\end{array}$ & $\begin{array}{l}40.0 \% \\
53.9 \% \\
25.0 \%\end{array}$ \\
\hline Western Medical Doctor & $\begin{array}{l}8 \text { Total } \\
6 \text { Males } \\
2 \text { Females }\end{array}$ & $\begin{array}{l}32.0 \% \\
46.2 \% \\
16.7 \%\end{array}$ \\
\hline Traditional Mexican American Healer & $\begin{array}{l}4 \text { Total } \\
1 \text { Male } \\
3 \text { Females }\end{array}$ & $\begin{array}{r}16.0 \% \\
7.7 \% \\
25.0 \%\end{array}$ \\
\hline Religious Leader & $\begin{array}{l}2 \text { Total } \\
1 \text { Male } \\
1 \text { Female }\end{array}$ & $\begin{array}{l}8.0 \% \\
7.7 \% \\
8.3 \%\end{array}$ \\
\hline Other & $\begin{array}{l}1 \text { Total } \\
1 \text { Female }\end{array}$ & $\begin{array}{l}4.0 \% \\
8.3 \%\end{array}$ \\
\hline
\end{tabular}


The data reported in this section is contingent upon the specific directions given for each subsection. Each of the questions of the first four subsections, relating to important social roles for men, women, elderly men, and elderly women, asked for three answers. Whereas, the last four subsections only asked for two answers each. Therefore, data collected for each of the first four subsections derives a total of 75 responses and data for each of the last four subsections derives from a total of 50 responses.

\section{Social Roles for a Mexican American Man}

According to the majority of the Mexican American participants of this study, the most important role for a man is that of a values teacher ( $n=19 ; 76 \%$ of the total sample, 11 males or $84.6 \%$ of the male sample and 8 females or $66.7 \%$ of the female sample). Other roles noted in decreasing order of popularity were: wage earner $(\underline{n}=18 ; 72 \%$ of the total sample, 10 males or $76.9 \%$ of the male sample and 8 females or $66.7 \%$ of the female sample), protector ( $n=18 ; 72 \%$ of the total sample, 9 males or $69.2 \%$ of the male sample and 9 females or $75 \%$ of the female sample), child/grandparent caretaker ( $\underline{n}=8$; $32 \%$ of the total sample, 3 males or $23.1 \%$ of the male sample and 5 females or $41.7 \%$ of the female sample), house maintainer ( $n=5 ; 20 \%$ of the total sample, 1 male or $7.7 \%$ of the male sample and 4 females or $33.3 \%$ of the female sample), housekeeper ( $\underline{n}=2 ; 8 \%$ of the total sample, 1 male or $7.7 \%$ of the male sample and 1 female or $8.3 \%$ of the female sample), those who checked "other" ( $\underline{n}=2 ; 8 \%$ of the total sample, 2 males or $15.4 \%$ of the male sample and 0 females), and money manager ( $\underline{n}=1 ; 4 \%$ of the total sample, 0 males and 1 female or $8.3 \%$ of the female sample). None of the participants believed that a 
cook would be an important social role for a man (see Table 12).

\section{Social Roles for a Mexican American Woman}

The most important social role for a woman in the Mexican American community, according to this sample of participants, was also that of a values teacher $(n=19 ; 76 \%$ of the total sample, 10 males or $76.9 \%$ of the male sample and 9 females or $75 \%$ of the female sample). Other roles noted in decreasing order of importance were: child/grandparent caretaker $(\underline{n}=17 ; 68 \%$ of the total sample, 10 males or $76.9 \%$ of the male sample and 7 females or $58.3 \%$ of the female sample), money manager ( $\underline{n}=8 ; 32 \%$ of the total sample, 3 males or $23.1 \%$ of the male sample and 5 females or $41.7 \%$ of the female sample), wage earner $(n=7 ; 28 \%$ of the total sample, 3 males or $23.1 \%$ of the male sample and 4 females or $33.3 \%$ of the female sample), protector ( $\underline{n}=5 ; 20 \%$ of the total sample, 1 male or $7.7 \%$ of the male sample and 4 females or $33.3 \%$ of the female sample), housekeeper $(n=5 ; 20 \%$ of the total sample, 2 males or $15.4 \%$ of the male sample and 3 females or $25 \%$ of the female sample), house maintainer ( $\underline{n}=5 ; 20 \%$ of the total sample, 3 males or $23.1 \%$ of the male sample and 2 females or $16.7 \%$ of the female sample), $\operatorname{cook}(\underline{n}=4 ; 16 \%$ of the total sample, 2 males or $15.4 \%$ of the male sample and 2 females or $16.7 \%$ of the female sample), and those who chose the "other" response ( $n=2 ; 8 \%$ of the total sample, 2 males or $15.4 \%$ of the male sample and 0 females) (see Table 13).

\section{Social Roles for an Older Mexican American Woman}

The most important social role for an older woman in the Mexican American community, according to the participants of this study, was also that of a values teacher $(\underline{n}=20 ; 80 \%$ of the total sample, 12 males or $92.3 \%$ of the male 
Table 12

Important Social Roles for a Mexican American Man ( $\mathrm{N}=25)$ :

\begin{tabular}{lcc}
\hline Social Role & Frequency & Percentage \\
\hline Values Teacher & 19 Total & $76.0 \%$ \\
& 11 Males & $84.6 \%$ \\
& 8 Females & $66.7 \%$ \\
Wage Earner & 18 Total & $72.0 \%$ \\
& 10 Males & $76.9 \%$ \\
& 8 Females & $66.7 \%$ \\
Protector & 18 Total & $72.0 \%$ \\
& 9 Males & $69.2 \%$ \\
Child/Grandparent Caretaker & 9 Females & $75.0 \%$ \\
& 8 Total & $32.0 \%$ \\
House Maintainer & 3 Males & $23.1 \%$ \\
& 5 Females & $41.7 \%$ \\
& 5 Total & $20.0 \%$ \\
Housekeeper & 1 Male & $7.7 \%$ \\
& 4 Females & $33.3 \%$ \\
& 2 Total & $8.0 \%$ \\
Other & 1 Male & $7.7 \%$ \\
& 1 Female & $8.3 \%$ \\
Money Manager & 2 Total & $8.0 \%$ \\
Cook & 2 Males & $15.4 \%$ \\
\hline
\end{tabular}


Table 13

Important Social Roles for a Mexican American Woman ( $\mathrm{N}=25)$ :

\begin{tabular}{|c|c|c|}
\hline Social Role & Frequency & Percentage \\
\hline Values Teacher & $\begin{array}{l}19 \text { Total } \\
10 \text { Males } \\
9 \text { Females }\end{array}$ & $\begin{array}{l}76.0 \% \\
76.9 \% \\
75.0 \%\end{array}$ \\
\hline Child/Grandparent Caretaker & $\begin{array}{l}17 \text { Total } \\
10 \text { Males } \\
7 \text { Females }\end{array}$ & $\begin{array}{l}68.0 \% \\
76.9 \% \\
58.3 \%\end{array}$ \\
\hline Money Manager & $\begin{array}{l}8 \text { Total } \\
3 \text { Males } \\
5 \text { Females }\end{array}$ & $\begin{array}{l}32.0 \% \\
23.1 \% \\
41.7 \%\end{array}$ \\
\hline Wage Earner & $\begin{array}{l}7 \text { Total } \\
3 \text { Males } \\
4 \text { Females }\end{array}$ & $\begin{array}{l}28.0 \% \\
23.1 \% \\
33.3 \%\end{array}$ \\
\hline Protector & $\begin{array}{l}5 \text { Total } \\
1 \text { Male } \\
4 \text { Females }\end{array}$ & $\begin{array}{r}20.0 \% \\
7.7 \% \\
33.3 \%\end{array}$ \\
\hline House Maintainer & $\begin{array}{l}5 \text { Total } \\
3 \text { Males } \\
2 \text { Females }\end{array}$ & $\begin{array}{l}20.0 \% \\
23.1 \% \\
16.7 \%\end{array}$ \\
\hline Housekeeper & $\begin{array}{l}5 \text { Total } \\
2 \text { Males } \\
3 \text { Females }\end{array}$ & $\begin{array}{l}20.0 \% \\
15.4 \% \\
25.0 \%\end{array}$ \\
\hline Cook & $\begin{array}{l}4 \text { Total } \\
2 \text { Males } \\
2 \text { Females }\end{array}$ & $\begin{array}{l}16.0 \% \\
15.4 \% \\
16.7 \%\end{array}$ \\
\hline Other & $\begin{array}{l}2 \text { Total } \\
2 \text { Males } \\
0 \text { Females }\end{array}$ & $\begin{array}{r}8.0 \% \\
15.4 \% \\
0.0 \%\end{array}$ \\
\hline
\end{tabular}


sample and 8 females or $66.7 \%$ of the female sample). Other roles identified as important in decreasing order of importance were: child caretaker $(\underline{n}=19 ; 76 \%$ of the total sample, 12 males or $92.3 \%$ of the male sample and 7 females or $58.3 \%$ of the female sample), protector ( $\underline{n}=6 ; 24 \%$ of the total sample, 2 males or $15.4 \%$ of the male sample and 4 females or $33.3 \%$ of the female sample), financial advisor ( $\mathrm{n}=6 ; 24 \%$ of the total sample, \pm male or $7.7 \%$ of the male sample and 5 females or $41.7 \%$ of the female sample), those who answered "other" ( $n=6 ; 24 \%$ of the total sample, 4 males or $30.8 \%$ of the male sample and 2 females or $8.3 \%$ of the female sample), house maintainer ( $n=4 ; 16 \%$ of the total sample, 2 males or $15.4 \%$ of the male sample and 2 females or $8.3 \%$ of the female sample), cook ( $\underline{n}=4 ; 16 \%$ of the total sample, 2 males or $15.4 \%$ of the male sample, and 2 females or $8.3 \%$ of the female sample), housekeeper $(\underline{n}=4$; $16 \%$ of the total sample, 1 male or $7.7 \%$ of the male sample and 3 females or $25 \%$ of the female sample), and money manager $(n=3 ; 12 \%$ of the total sample, 1 male or $7.7 \%$ of the male sample and 2 females or $8.3 \%$ of the female sample) (see Table 14).

\section{Social Roles for an Older Mexican American Man}

The most important role for an older man in the Mexican American community, according to the participants of this study, was also that of values teacher $(\underline{n}=20 ; 80 \%$ of the total sample, 10 males or $76.9 \%$ of the male sample and 10 females or $\mathbf{8 3 . 3} \%$ of the female sample). Other social roles identified in decreasing order of importance were: child caretaker $(\underline{n}=13 ; 52 \%$ of the total sample, 9 males or $69.2 \%$ of the male sample and 4 females or $33.3 \%$ of the female sample), protector ( $\underline{n}=10 ; 40 \%$ of the total sample, 5 males or $38.5 \%$ of 
Table 14

Important Social Roles for an Older Mexican American Woman ( $\mathrm{N}=25$ ):

\begin{tabular}{|c|c|c|}
\hline Social Role & Frequency & Percentage \\
\hline Values Teacher & $\begin{array}{l}20 \text { Total } \\
12 \text { Males } \\
8 \text { Females }\end{array}$ & $\begin{array}{l}80.0 \% \\
92.3 \% \\
66.7 \%\end{array}$ \\
\hline Child Caretaker & $\begin{array}{l}19 \text { Total } \\
12 \text { Males } \\
7 \text { Females }\end{array}$ & $\begin{array}{l}76.0 \% \\
92.3 \% \\
58.3 \%\end{array}$ \\
\hline Financial Advisor & $\begin{array}{l}6 \text { Total } \\
1 \text { Male } \\
5 \text { Females }\end{array}$ & $\begin{array}{r}24.0 \% \\
7.7 \% \\
41.7 \%\end{array}$ \\
\hline Protector & $\begin{array}{l}6 \text { Total } \\
2 \text { Males } \\
4 \text { Females }\end{array}$ & $\begin{array}{l}24.0 \% \\
15.4 \% \\
33.3 \%\end{array}$ \\
\hline Other & $\begin{array}{l}6 \text { Total } \\
4 \text { Males } \\
2 \text { Females }\end{array}$ & $\begin{array}{l}24.0 \% \\
30.8 \% \\
16.7 \%\end{array}$ \\
\hline House Maintainer & $\begin{array}{l}4 \text { Total } \\
2 \text { Males } \\
2 \text { Females }\end{array}$ & $\begin{array}{l}16.0 \% \\
15.4 \% \\
16.7 \%\end{array}$ \\
\hline Cook & $\begin{array}{l}4 \text { Total } \\
2 \text { Males } \\
2 \text { Females }\end{array}$ & $\begin{array}{l}16.0 \% \\
15.4 \% \\
16.7 \%\end{array}$ \\
\hline Housekeeper & $\begin{array}{l}4 \text { Total } \\
1 \text { Male } \\
3 \text { Females }\end{array}$ & $\begin{array}{r}16.0 \% \\
7.7 \% \\
25.0 \%\end{array}$ \\
\hline Money Manager & $\begin{array}{l}3 \text { Total } \\
1 \text { Male } \\
2 \text { Females }\end{array}$ & $\begin{array}{r}12.0 \% \\
7.7 \% \\
16.7 \% \\
\end{array}$ \\
\hline
\end{tabular}


the male sample and 5 females or $41.7 \%$ of the female sample), house maintainer ( $n=8 ; 32 \%$ of the total sample, 4 males or $30.8 \%$ of the male sample and 4 females or $33.3 \%$ of the female sample), financial advisor ( $n=6 ; 24 \%$ of the total sample, 3 males or $23.1 \%$ of the male sample and 3 females or $25 \%$ of the female sample), those who answered "other" ( $\underline{n}=6 ; 24 \%$ of the total sample, 4 males or $30.8 \%$ of the male sample and 2 females or $8.3 \%$ of the female sample), money manager $(\underline{n}=5 ; 20 \%$ of the total sample, 2 males or $15.4 \%$ of the male sample and 3 females or $25 \%$ of the female sample), cook $(\underline{n}=3 ; 12 \%$ of the total sample, 0 males and 3 females or $25 \%$ of the female sample), and housekeeper $(\underline{n}=2 ; 8 \%$ of the total sample with 1 male or $7.7 \%$ of the male sample and 1 female or $8.3 \%$ of the female sample) (see Table 15).

Social Roles for a Male Mexican American Teenager The most important social role for a male teenager in the Mexican American community, according to this study's participants, was that of school student $(\underline{n}=24 ; 96 \%$ of the total sample, 13 males or $100 \%$ of the male sample and 11 females or $91.7 \%$ of the female sample). The other responses in order of decreasing importance were: house maintenance helper $(\underline{n}=11 ; 44 \%$ of the total sample, 9 males or $69.2 \%$ of the male sample and 2 females or $8.3 \%$ of the female sample), sports participant ( $\underline{n}=7 ; 28 \%$ of the total sample, 2 males or $15.4 \%$ of the male sample and 5 females or $41.7 \%$ of the female sample), wage earner $(\underline{n}=6 ; 24 \%$ of the total sample, 2 males or $15.4 \%$ of the male sample and 4 females or $33.3 \%$ of the female sample), cook ( $\underline{n}=2 ; 8 \%$ of the total sample, 1 male or $7.7 \%$ of the male sample and 1 female or $8.3 \%$ of the female sample), child care helper $(\underline{n}=1 ; 4 \%$ of the total sample, 0 males and 1 female or $8.3 \%$ of 
Table 15

Important Social Roles for an Older Mexican American Man ( $\mathrm{N}=25)$ :

\begin{tabular}{|c|c|c|}
\hline Social Role & Frequency & Percentage \\
\hline Values Teacher & $\begin{array}{l}20 \text { Total } \\
10 \text { Males } \\
10 \text { Females }\end{array}$ & $\begin{array}{l}80.0 \% \\
76.9 \% \\
83.3 \%\end{array}$ \\
\hline Child Caretaker & $\begin{array}{l}13 \text { Total } \\
9 \text { Males } \\
4 \text { Females }\end{array}$ & $\begin{array}{l}52.0 \% \\
69.2 \% \\
33.3 \%\end{array}$ \\
\hline Protector & $\begin{array}{l}10 \text { Total } \\
5 \text { Males } \\
5 \text { Females }\end{array}$ & $\begin{array}{l}40.0 \% \\
38.5 \% \\
41.7 \%\end{array}$ \\
\hline House Maintainer & $\begin{array}{l}8 \text { Total } \\
4 \text { Males } \\
4 \text { Females }\end{array}$ & $\begin{array}{l}32.0 \% \\
30.8 \% \\
33.3 \%\end{array}$ \\
\hline Other & $\begin{array}{l}6 \text { Total } \\
4 \text { Males } \\
2 \text { Females }\end{array}$ & $\begin{array}{l}24.0 \% \\
30.8 \% \\
16.7 \%\end{array}$ \\
\hline Financial Advisor & $\begin{array}{l}6 \text { Total } \\
3 \text { Males } \\
3 \text { Females }\end{array}$ & $\begin{array}{l}24.0 \% \\
23.1 \% \\
25.0 \%\end{array}$ \\
\hline Money Manager & $\begin{array}{l}5 \text { Total } \\
2 \text { Males } \\
3 \text { Females }\end{array}$ & $\begin{array}{l}20.0 \% \\
15.4 \% \\
25.0 \%\end{array}$ \\
\hline Cook & $\begin{array}{l}3 \text { Total } \\
3 \text { Females }\end{array}$ & $\begin{array}{l}12.0 \% \\
25.0 \%\end{array}$ \\
\hline Housekeeper & $\begin{array}{l}2 \text { Total } \\
1 \text { Male } \\
1 \text { Female }\end{array}$ & $\begin{array}{c}8.0 \% \\
7.7 \% \\
8.3 \% \\
\end{array}$ \\
\hline
\end{tabular}


the female sample), and housekeeper ( $\underline{n}=1 ; 4 \%$ of the total sample, 0 males and 1 female or $8.3 \%$ of the female sample). None of the participants chose the "other" response (see Table 16).

\section{Social Roles for a Female Mexican American Teenager}

The most important social role for a female teenager in the Mexican American community, according to this study's participants, was that of school student ( $\underline{n}=24 ; 96 \%$ of the total sample, 13 males or $100 \%$ of the male sample and 11 females or $91.7 \%$ of the female sample). Other responses in order of decreasing frequency were: child care helper ( $\underline{n}=10 \quad 40 \%$ of the total sample, 6 males or $46.2 \%$ of the male sample and 4 females or $33.3 \%$ of the female sample), house maintainer ( $\mathrm{n}=7 ; 28 \%$ of the total sample, 3 males or $23.1 \%$ of the male sample and 4 females or $33.3 \%$ of the female sample), sports participant ( $\underline{n}=6 ; 24 \%$ of the total sample, 4 males or $30.8 \%$ of the male sample and 2 females or $8.3 \%$ of the female sample), wage earner $(n=4 ; 16 \%$ of the total sample, 1 male or $7.7 \%$ of the male sample and 3 females or $25 \%$ of the female sample), housekeeper ( $\underline{n}=1 ; 4 \%$ of the total sample, 1 male or $7.7 \%$ of the male sample and no females), and those who chose "other" ( $\underline{n}=1 ; 4 \%$ of the total sample, 1 male or $7.7 \%$ of the male sample and no females) and wrote-in "house maintenance helper". None of the participants indicated that a cook would be an important social role for a female teenager (see Table 17).

\section{Social Roles for a Mexican American Male Child}

The most important social role for a boy in the Mexican American community, according to this study's participants, was that of school student $(\underline{n}=24 ; 96 \%$ of the total sample, 13 males or $100 \%$ of the male sample and 11 
Table 16

Important Social Roles for a Male Mexican American Teenager ( $\mathrm{N}=25)$ :

\begin{tabular}{llr}
\hline Social Role & Frequency & Percentage \\
\hline School Student & 24 Total & $96.0 \%$ \\
& 13 Males & $100.0 \%$ \\
& 11 Females & $91.7 \%$ \\
House Maintenance Helper & 11 Total & $44.0 \%$ \\
& 9 Males & $69.2 \%$ \\
& 2 Females & $16.7 \%$ \\
Sports Participant & 7 Total & $28.0 \%$ \\
& 2 Males & $15.4 \%$ \\
Wage Earner & 5 Females & $41.7 \%$ \\
& 6 Total & $24.0 \%$ \\
& 2 Males & $15.4 \%$ \\
Cook & 4 Females & $33.3 \%$ \\
& 2 Total & $8.0 \%$ \\
& 1 Male & $7.7 \%$ \\
Child Care Helper & 1 Female & $8.3 \%$ \\
& 1 Total & $4.0 \%$ \\
Housekeeper & 1 Female & $8.3 \%$ \\
& 1 Total & $4.0 \%$ \\
Other & 1 Female & $8.3 \%$ \\
\hline
\end{tabular}


Table 17

Important Social Roles for a Female Mexican American Teenager ( $N=25)$ :

\begin{tabular}{|c|c|c|}
\hline Social Role & Frequency & Percentage \\
\hline School Student & $\begin{array}{l}24 \text { Total } \\
13 \text { Males } \\
11 \text { Females }\end{array}$ & $\begin{array}{r}96.0 \% \\
100.0 \% \\
91.7 \%\end{array}$ \\
\hline Child Care Helper & $\begin{array}{l}10 \text { Total } \\
6 \text { Males } \\
4 \text { Females }\end{array}$ & $\begin{array}{l}40.0 \% \\
46.2 \% \\
33.3 \%\end{array}$ \\
\hline House Maintainer & $\begin{array}{l}7 \text { Total } \\
3 \text { Males } \\
4 \text { Females }\end{array}$ & $\begin{array}{l}28.0 \% \\
23.1 \% \\
33.3 \%\end{array}$ \\
\hline Sports Participant & $\begin{array}{l}6 \text { Total } \\
4 \text { Males } \\
2 \text { Females }\end{array}$ & $\begin{array}{l}24.0 \% \\
30.8 \% \\
16.7 \%\end{array}$ \\
\hline Wage Earner & $\begin{array}{l}4 \text { Total } \\
1 \text { Male } \\
3 \text { Females }\end{array}$ & $\begin{array}{r}16.0 \% \\
7.7 \% \\
25.0 \%\end{array}$ \\
\hline Housekeeper & $\begin{array}{l}1 \text { Total } \\
1 \text { Male }\end{array}$ & $\begin{array}{l}4.0 \% \\
7.7 \%\end{array}$ \\
\hline Other & $\begin{array}{l}1 \text { Total } \\
1 \text { Male }\end{array}$ & $\begin{array}{l}4.0 \% \\
7.7 \%\end{array}$ \\
\hline Cook & 0 Total & $0.0 \%$ \\
\hline
\end{tabular}


females or $91.7 \%$ of the female sample). Other responses to this question were: player/sports participant ( $\underline{n}=18 ; 72 \%$ of the total sample, 9 males or $69.2 \%$ of the male sample and 9 females or $75 \%$ of the female sample), house maintenance helper ( $\underline{n}=6 ; 24 \%$ of the total sample, 5 males or $38.5 \%$ of the male sample and 1 female or $8.3 \%$ of the female sample), housekeeping helper ( $n=3 ; 12 \%$ of the total saniple, with no males, and 3 females or $25 \%$ of the female sample), and cooking helper ( $n=1 ; 4 \%$ of the total sample, 1 male or $7.7 \%$ of the male sample and no females). None of the participants perceived that the roles of child care helper or wage earner were important for a boy child. Also, none of the participants chose the "other" response (see Table 18).

\section{Social Roles for a Mexican American Female Child}

The majority of the participants believed that the most important social role for a girl in the Mexican American community was that of school student ( $\underline{n}=24 ; 96 \%$ of the total sample, 12 males or $92.3 \%$ of the male sample and 12 females or $100 \%$ of the female sample). Other social roles that the participants of this study perceived as important for a girl were: player/sports participant ( $\underline{n}=15 ; 60 \%$ of the total sample, 9 males or $69.2 \%$ of the male sample and 6 females or $50 \%$ of the female sample), housekeeping helper ( $n=4$ or $16 \%$ of the total sample, 2 males or $15.4 \%$ of the male sample and 2 females or $8.3 \%$ of the female sample), cooking helper ( $\underline{n}=4$ or $16 \%$ of the total sample, 3 males or $23.1 \%$ of the male sample and 1 female or $8.3 \%$ of the female sample), house maintenance helper $(n=3 ; 12 \%$ of the total sample, 3 males or $23.1 \%$ of the male sample and no females), child care helper ( $\underline{n}=2 ; 8 \%$ of the total sample, with no males and 2 females or $8.3 \%$ of the female sample), and wage earner 
Table 18

Important Social Roles for a Mexican American Male Child ( $\mathrm{N}=25)$ :

\begin{tabular}{|c|c|c|}
\hline Social Role & Frequency & Percentage \\
\hline School Student & $\begin{array}{l}24 \text { Total } \\
13 \text { Males } \\
11 \text { Females }\end{array}$ & $\begin{array}{r}96.0 \% \\
100.0 \% \\
91.7 \%\end{array}$ \\
\hline Player/Sports Participant & $\begin{array}{l}18 \text { Total } \\
9 \text { Males } \\
9 \text { Females }\end{array}$ & $\begin{array}{l}72.0 \% \\
69.2 \% \\
75.0 \%\end{array}$ \\
\hline House Maintenance Helper & $\begin{array}{l}6 \text { Total } \\
5 \text { Males } \\
1 \text { Female }\end{array}$ & $\begin{array}{r}24.0 \% \\
38.5 \% \\
8.3 \%\end{array}$ \\
\hline Housekeeping Helper & $\begin{array}{l}3 \text { Total } \\
0 \text { Males } \\
3 \text { Females }\end{array}$ & $\begin{array}{c}12.0 \% \\
0.0 \% \\
25.0 \%\end{array}$ \\
\hline Cooking Helper & $\begin{array}{l}1 \text { Total } \\
1 \text { Male } \\
0 \text { Females }\end{array}$ & $\begin{array}{l}4.0 \% \\
7.7 \% \\
0.0 \%\end{array}$ \\
\hline Child care Helper & $\begin{array}{l}0 \text { Total } \\
0 \text { Males } \\
0 \text { Females }\end{array}$ & $\begin{array}{l}0.0 \% \\
0.0 \% \\
0.0 \%\end{array}$ \\
\hline Wage Earner & $\begin{array}{l}\text { 0 Total } \\
\text { 0 Males } \\
\text { O Females }\end{array}$ & $\begin{array}{l}0.0 \% \\
0.0 \% \\
0.0 \%\end{array}$ \\
\hline Other & $\begin{array}{l}0 \text { Total } \\
0 \text { Males } \\
0 \text { Females }\end{array}$ & $\begin{array}{l}0.0 \% \\
0.0 \% \\
0.0 \%\end{array}$ \\
\hline
\end{tabular}


( $\underline{n}=2 ; 8 \%$ of the total sample, no males and 2 females or $8.3 \%$ of the female sample). None of the participants chose the "other" response (see Table 19).

\section{Goal of Rehabilitation}

For this subsection, participants were asked to give their view on the primary goal of rehabilitation therapy for a person with a disability. Given four options, the majority of the participants believed that the primary goal of rehabilitation was equal emphasis on acceptance of limitations resulting from disability and learning methods and techniques to affect change ( $\underline{n}=22 ; 88 \%$ of the total sample, 11 males or $84.6 \%$ of the male sample and 11 females or $91.7 \%$ of the female sample). The rest of the participants believed the goal of rehabilitation is to emphasize learning methods and techniques to affect change with minimal acceptance of limitations resulting from the disability $(n=3$; $12 \%$ of the total sample, 2 males or $15.4 \%$ of the male sample and 1 female or $8.3 \%$ of the female sample). None of the participants indicated that the primary goal of rehabilitation should be emphasis on acceptance of limitations resulting from the disability with minimal learning of methods and techniques to affect change. Also, none of the participants chose to write in a response.

\section{Having a Person with a Disability in the Family}

When asked if they had a person with a disability in their family, the majority of the participants indicated they did not $(\underline{n}=18 ; 72 \%$ of the total sample, 9 males or $69.2 \%$ of the male sample and 9 females or $75 \%$ of the female sample). Seven of the participants indicated that they had a person with a disability in their family ( $28 \%$ of the total sample, 4 males or $30.8 \%$ of the male sample and 3 females or $25 \%$ of the female sample). 
Table 19

Important Social Roles for a Mexican American Female Child ( $N=25)$ :

\begin{tabular}{|c|c|c|}
\hline Social Role & Frequency & Percentage \\
\hline School Student & $\begin{array}{l}24 \text { Total } \\
12 \text { Males } \\
12 \text { Females }\end{array}$ & $\begin{array}{l}96.0 \% \\
92.3 \% \\
100 \%\end{array}$ \\
\hline Player/Sports Participant & $\begin{array}{l}15 \text { Total } \\
9 \text { Males } \\
6 \text { Females }\end{array}$ & $\begin{array}{l}60.0 \% \\
69.2 \% \\
50.0 \%\end{array}$ \\
\hline Housekeeping Helper & $\begin{array}{l}4 \text { Total } \\
2 \text { Males } \\
2 \text { Females }\end{array}$ & $\begin{array}{l}16.0 \% \\
15.4 \% \\
16.7 \%\end{array}$ \\
\hline Cooking Helper & $\begin{array}{l}4 \text { Total } \\
3 \text { Males } \\
1 \text { Female }\end{array}$ & $\begin{array}{r}16.0 \% \\
23.1 \% \\
8.3 \%\end{array}$ \\
\hline House Maintenance Helper & $\begin{array}{l}3 \text { Total } \\
3 \text { Males }\end{array}$ & $\begin{array}{l}12.0 \% \\
23.1 \%\end{array}$ \\
\hline Child care He!per & $\begin{array}{l}2 \text { Total } \\
2 \text { Females }\end{array}$ & $\begin{array}{r}8.0 \% \\
16.7 \%\end{array}$ \\
\hline Wage Earner & $\begin{array}{l}2 \text { Total } \\
2 \text { Females }\end{array}$ & $\begin{array}{r}8.0 \% \\
16.7 \%\end{array}$ \\
\hline Other & 0 Total & $0.0 \%$ \\
\hline
\end{tabular}


Of those that said they had a person with a disability in their family, three indicated that the person was a grandparent (12\% of the total sample, with 1 male or $7.7 \%$ of the male sample, and 2 females or $8.3 \%$ of the female sample), one indicated that it was his parent ( $4 \%$ of the total sample or $7.7 \%$ of the male sample and 0 females), one indicated that it was her uncle/aunt ( $4 \%$ of the total sample or $8.3 \%$ of the female sample and 0 males), one indicated that the person was his cousin ( $4 \%$ of the total sample or $7.7 \%$ of the male sample and 0 females), and one indicated that the person with a disability was himself ( $4 \%$ of the total sample or $7.7 \%$ of the male sample and 0 females).

\section{Use of Community Based Programs}

All of the participants were asked if someone in his/her family had a severe disability and was living at home, would he/she make use of community based programs for people with disabilities? The majority of the participants indicated "yes", that they would make use of community based programs for people with disabilities $(\underline{n}=21 ; 84 \%$ of the total sample, 12 males or $92.3 \%$ of the male sample and 9 females or $75 \%$ of the female sample). The most common theme given as explanation for the affirmative answer was that "if the programs would make it easier for the family and person with a disability" to cope and "if they would help the caretaker to learn how to take care of the person with a disability better," then "they should be used" ( $n=16 ; 64 \%$ of the total sample, 10 males or $76.9 \%$ of the male sample and 6 females or $50 \%$ of the female sample suggested this theme in their answers). Other explanations provided for the affirmative answer were: "for activities like shopping and traveling" community help would be useful, "but not for personal activities" for 
which the family is expected to help ( $n=1$ female, $4 \%$ of the total sample and 8.3\% of the female sample), that community programs should be used for "their experience and understanding of the situation", since "the family can not truly relate" to the person with a disability ( $\underline{n}=1$ female, $4 \%$ of the total sample and $8.3 \%$ of the female sample), and "so that maybe the person with a disability can get some counseling and take part in activities that require special materials or environments that are not found or cannot be accommodated in the home $(\underline{n}=1$ female, $4 \%$ of the total sample and $8.3 \%$ of the female sample). Finally, one person stated that "education is the key to everything" ( $\underline{n}=1$ female, $4 \%$ of the total sample and $8.3 \%$ of the female sample).

None of the participants indicated that they would not take advantage of community based programs for people with disabilities if the person with a disability was living at home. However, three explained that they were not sure if they would or not (12\% of the total sample, 1 male or $7.7 \%$ of the male sample and 2 females or $\mathbf{8 . 3 \%}$ of the female sample). They gave explanations like: "it depends on the program and what it offers" $(\underline{n}=1$ male or $7.7 \%$ of the male sample and $4 \%$ of the total sample), or that "it would be up to the person with a disability" ( $\underline{n}=1$ female or $8.3 \%$ of the female sample and $4 \%$ of the total sample).

\section{Results}

The findings of this research are as follows:

(1) What are the Activities of Daily Living (ADL) that Mexican American people believe to be the most important to perform independently by a person with a disability? 
According to the respondents for this study, the three most important Activities of Daily Living (ADL) to be performed independently by a person with a disability are toileting, eating, and bathing.

(2) What are the perceptions held by Mexican Americans regarding independence of a person with a disability in the family, quality of assistance given, and amount of assistance provided?

The respondents in this study reported that in regard to independence of a person with a disability in the family, most children of parents with a disability and most parents of a child with a disability would feel obligated to assist their child/parent for various reasons. Some of these reasons included providing assistance due to a moral/ethical obligation, because of an unspoken sense of responsibility, because "Mexican Americans do not believe in [putting ill/disabled family members into] convalescent hospitals," and because of a belief in "reciprocation of help" for children (of a parent with a disability) since that parent helped to raise them, or because "parents are more experienced, knowledgeable and are the main support system for the child [with a disability] and the family." However, participants in this study perceived that if the child/parent with a disability did not want assistance, it would be okay for the parent to let the child with a disability do the activities (ADL) independently. In essence, it would be acceptable to maintain the interdependent status quo within the family but the children of a parent with a disability would most likely be unsure of a decision to allow their father or mother to perform activities of daily living independently based on the type and severity of the disability versus the capability of the family member with a disability to perform certain or all 
Activities of Daily Living.

In regard to quality of assistance provided for a family member with a disability, the majority of the study respondents reported they would feel most comfortable with a female in the family providing assistance.

In regard to amount of assistance provided, the study sample believed that people of Mexican American descent with disabilities would be most willing to accept assistance with meal preparation, housekeeping and house maintenance, and would feel most obligated to accept assistance with meal preparation and toileting activities. This sample also perceived that Mexican American parents would feel most obligated to lend assistance with toileting and bathing should their child have a disability, and that Mexican American children would feel most obligated to lend assistance with meal preparation for a parent with a disability. Again, this sample felt that most parents would allow their child with a disability to perform Activities of Daily Living independently if that is what their child wanted, but that most children of a parent with a disability would be unsure in their decision to allow their parent to perform activities independently.

(3) What do Mexican Americans consider to be the primary social roles of older adult males and females over 60 , of adults ages 40 to 59 years, of young adults ages 20 to 39 years, and of teenagers and boy and girls ages 0 to 19 years?

The respondents in this study reported the primary social roles, in order of importance, for Mexican American older adult males over 60 to be: values teacher, followed by a child caretaker, protector, house maintainer, other 
(untitled roles), financial advisor, money manager, cook and housekeeper.

The primary social roles, in order of importance, for Mexican American older adult females over 60 are: values teacher, child caretaker, financial advisor, protector, other (untitled roles), house maintainer, cook, housekeeper and money manager.

The primary social roles, in order of importance, for Mexican American adult males ages 20 to 59 are: values teacher, wage earner, protector, child/grandparent caretaker, house maintainer, housekeeper, other (untitled roles), money manager and cook.

The primary social roles, in order of importance, for Mexican American adult females ages 20 to 59 are: values teacher, child/grandparent caretaker, money manager, wage earner, protector, house maintainer, housekeeper, cook and other (untitled roles).

According to the respondents of this study, the primary social roles, in order of importance, for Mexican American male teenagers are: school student, house maintenance helper, sports participant, wage earner, cook, child care helper, housekeeper and other (untitled roles).

The primary social roles, in order of importance, reported for Mexican American female teenagers are: school student, child care helper, house maintainer, sports participant, wage earner, housekeeper, other (untitied roles) and cook.

The most important social roles, in order of importance, reported for Mexican American male children are: school student, player/sports participant, house maintenance helper, housekeeping helper, cooking helper, child care 
helper, wage earner and other (untitled roles).

Finally, the most important social roles, in order of importance, reported for Mexican American female children are: school student, player/sports participant, housekeeping helper, cooking helper, house maintenance helper, child care helper, wage earner, and other (untitled roles).

(4) What do Mexican Americans perceive as the primary goal of rehabilitation for a person with a disability at different ages across the lifespan?

The majority of the participants in this study reported that the primary goal of rehabilitation for a person with a disability was equal emphasis on acceptance of limitations resulting from disability and learning methods and techniques to affect change.

(5) What are the perceptions of Mexican Americans toward the use of community based resources for people with disabilities?

The majority of respondents in this study agreed that if someone in his/her family had a severe disability and was living at home, then he/she would make use of community based programs for people with disabilities, mostly with the hope that the programs would make it easier for the family and person with a disability to cope and help the caretaker(s) to learn how to take better care of the person with a disability. 


\section{CHAPTER 5 \\ DISCUSSION OF RESULTS, PROFESSIONAL IMPLICATIONS, AND RECOMMENDATIONS}

The purpose of this study was to contribute to knowledge regarding perspectives on issues of dependence versus independence of people with disabilities within the Mexican-American community of Santa Clara County, California. People of Mexican-American descent were chosen as the sample for this study since they are part of the largest ethnic minority group in the County of Santa Clara and in the state of California, and part of the fastest growing ethnic minority group in the United States (Gann \& Duignan, 1986). Given this growth pattern, it is important for health care professionals, as well as other individuals in the general population, to understand the cultural beliefs of people of Mexican-American origin so that culturally relevant care can be provided. The role expectations of male and female members at different stages across the lifespan within the community were also explored in order to ascertain the importance of various activities and skills in the daily lives of people of MexicanAmerican descent.

This research examined the concept that people perceive, experience and cope with health concerns based on the instilled beliefs, customs and values with which they have grown up (Bauwens \& Anderson, 1992). Many of the traditional health care practices, help-seeking tendencies, views on etiology of illness/disability, ways of coping and communicating, and world views of Mexican Americans in the United States are different from those 
of the dominant majority of Americans and are therefore often misunderstood (Kraft, 1979). In addition, it has become apparent that many of the traditional models of medicine and healing which come from the Latino/Mexican culture (from which Mexican Americans derive) do not comply with the scientific/pathological/linear model which those from the dominant culture within the United States tend to value (Lea, 1994). Yet, when people from a traditional culture, such as Mexican Americans, encounter disability in the United States, they can be placed in situations in which the Western medical approach is the only practical alternative for them. Perhaps, many of the subjects who participated in this study have found themselves adopting Western ways of thinking, to the point that their traditional methods of caring and treatment for the sick and disabled no longer seem practical. Perhaps, this is why many of their responses to questions tended toward a more progressive point of view (rather than a more traditional manner). Many times, occupational therapists and other health practitioners who work from a medical model will focus on a given patient or situation solely from the Western medical perspective that they learned in health profession schooling, forgetting that their patient may hoid a totally different set of values regarding his/her condition. It is during these types of predicaments that Western health care practitioners/occupational therapists can misconstrue certain behaviors/symptoms of illness and/or disability which can lead to misdiagnosis and/or inappropriate treatment for the patient.

In order to prevent breakdown in communication which can easily result from a situation as described above, occupational therapists must learn to recognize behaviors and performance roles outside the context of their own 
dominant culture when assessing their Mexican American patients. It is important for therapists to become more knowledgeable about the culturally based health belief systems and practices of the Mexican American culture and to apply this knowledge to their assessments and treatment planning for their Mexican American patients.

Also, occupational therapists working with patients of Mexican American descent should become more aware of their patient's cultural beliefs towards rehabilitative treatments and procedures since many may hold a more traditional outlook towards family, feeling more comfortable with and obligated toward receiving assistance from family care givers, even when their functional status may be such that independent performance of certain ADL could be accomplished. In fact, interdependent relationships may be the foundation of the patient's family structure if he/she comes from a more traditional Mexican American family (those who uphold the customs of their native culture). As such, the patient's family may exist as the main source of support for the patient which he/she might otherwise receive from a community program.

Independence in Activities of Daily Living

\section{Perspectives of a Person with a Disability}

The Mexican American subjects (84\%) who participated in this study reported toileting as the Activity of Daily Living (ADL) which they felt a person with a severe disability would most likely want to perform independently. Eating and bathing were the next most important activities to be performed independently by a person with a disability. Dressing, being able to operate a wheelchair, grooming, meal preparation, and housekeeping were ranked as 
less important for independent performance. Child care and house maintenance were not ranked as having any importance for independent performance by a person with a disability. However, since subjects could not rank any of the activities of daily living equally, it must be kept in mind that the ranking of importance is a forced ranking.

The activity with which the majority of subjects believed a person with a disability would most likely accept support was meal preparation ( $88 \%$ of the subjects answered this way). Help with housekeeping (76\%) and house maintenance duties $(72 \%)$ closely followed in their importance. When it came to feelings of obligation, the results demonstrated a rather broad set of beliefs. However, a majority of subjects responded that a person with a severe disability would probably feel obliged to accept irelp with the activities of meal preparation (32\%) and toileting (32\%) first, followed by bathing (28\%) and house maintenance (28\%). It is interesting to note, that even though toileting was reported as the most important activity to be performed independently, the subjects of this study tended to believe that a person with a disability would be obliged to accept help with this ADL, if need be. There were also a strong number of subjects (24\%) who believed that a person with a disability would not feel at all obligated to accept any assistance with any ADL.

\section{Perspective of the Family Member}

The results indicated that the subjects expected (92\%) that the parents of a child with a disability would help their child with certain ADL. However, a stronger need to help was indicated from the son/daughter's perspective to assist their parent, should he/she have a disability ( $100 \%$ of the subject pool 
agreed).

As indicated from these results, the parents of a child with a disability would feel it most important to assist their child with toileting, bathing and eating more readily than with any other ADL. Two of these ADL, toileting and bathing, fall into agreement with the activities with which the person with a disability would probably feel most obligated to accept assistance.

From the perspective of a son or daughter with a parent with a severe disability, the three most important activities with which to assist the parent were meal preparation, eating, and house maintenance. Again, two of these, meal preparation and house maintenance are in agreement with the activities with which a person with a disability would probably feel most obligated to accept assistance. Toileting was also selected often (especially from the female subjects $=50 \%$ agreed) as a task for a son or daughter to help their parent with a disability with. This particular ADL also coincides with the top choices for which a person with a disability might feel most obligated to accept assistance. Eating was the only similar ADL for which a son/daughter or mother/father with a disability would most likely feel obligated to accept assistance.

Given the context of a family member who was disabled and who wanted to perform their ADL independently, the Mexican American subjects of this study (especially the female subjects $=66.7 \%$ agreed) expected the parents of a child with a disability to let their child do these activities by him/herself. However, given the situation in which the mother or father had a disability, the majority of subjects indicated that they were uncertain as to whether the son/daughter should let their parent perform these activities on their own. 
The concept of independence within the family can vary from family to family within any given culture. However, the values of the dominant culture usually tend to predominate, pushing the values of the family into accord. The answers the majority of the Mexican American subjects gave to the questions pertaining to independence in activities of daily living for a family member with a severe disability suggest that either the subjects themselves hold the concept of independence as important or that they might have been influenced by other cultural values presented to them in their daily lives in the United States (or at San Jose State University). This is suggested in the fact that a majority of Mexican American subjects for this study thought it important for a family member with a child with a disability to let their child perform their ADL independently if he/she so chose. This stance towards independence runs contradictory to the picture portrayed in the literature on Mexican American families, which emphasizes family inteidependence.

\section{Quality and Amount of Assistance Preference Regarding Familial Relationship and Gender of Caretakers and Therapists}

A majority from both the male and female subjects of this study expected that a family member with a disakility would prefer a caretaker for self-care (eating, dressing, bathing, toileting, grooming) to be a female in the family. There was no preference for the gender of the therapist who would train the person with a disability in self-care activities if he/she so needed. 


\section{Influential Individuals}

\section{in the Family's Decision to Offer Assistance}

The two people most often selected by this Mexican American sample as having the most influence in the decision of whether or not to lend assistance were the person with the disability him/herself (whether it is a child with a disability or a parent with a disability) and the attending therapist (this includes most specifically occupational therapists) working with the person with disability on self-care activities. These choices were made by the sample in both the case of the child with a disability and the parent with a disability.

For occupational therapists working with the person with a disability (child, parent, or grandparent), it is apparent that the person's family is a crucial element in the rehabilitation process. At times, occupational therapists will find that they can work with the members of a family effectively in ways that will serve to elicit maximum independent functioning of the patient in performing certain activities of daily living (ADL). At other times or for certain daily life activities, occupational therapists will need to accept the fact of interdependence within the family, which can reinforce the patient's expectation for assistance and prevent the individual members of the family from allowing the patient to perform more independently. In these cases, occupational therapists might be able to make a larger difference for the patient and his/her family by focusing more attention on family education and assistance training. Interestingly, the western medical doctor was reported more frequently than the traditional Mexican American healer as a power for influencing the family's decision to offer or not offer assistance to their loved one with a 
disability. This could indicate the westernization of this study's Mexican American sample as they have become more educated and may have turned away from traditional Hispanic, non-scientific methods of healing. However, tradition appeared to be a factor in the responses that the oldest family member was ranked third highest of influential people in the family's decision regarding whether or not to lend assistance in ADL for a child or parent with a severe disability.

\section{Social Roles in Mexican American Community Life}

Roles, according to Burke (as cited in Stearns, 1988), "provide a framework for daily activities", as well as give them meaning and value. An essential element in the development and performance of roles is the patient's culture. Cultural expectations for the individual patient, as explained by Davidson (1991), are shaped by the beliefs, attitudes, values, and customs of the social group to which that patient associates him/herself. With this in mind, it is important for the occupational therapist working with the person with a disability and their family to understand the meaning and significance of the patient's roles within the community of which he/she is a part. Upon identification of specific important roles for the patient, the occupational therapist will be able to apply his/her knowledge more effectively to help the patient perform his/her roles in a way that meet the cultural expectations of the patient him/herself and of his/her family.

The three most important social roles for a Mexican American man, according to the subjects of this study (in descending order of the possible choices given) were values teacher, wage earner, and protector. For Mexican 
American women, the most important roles were values teacher, child/grandparent caretaker, and money manager.

The results showed the important role of values teacher continuing into old age for both men and women. The role of child caretaker was viewed as the second most important role for elderly men and women of Mexican American descent. While the third most important role for elderly Mexican American women was that of financial advisor, the role of protector was carried over for elderly Mexican American men.

For Mexican American teenagers the role of school student held the highest importance for both males and females. The second and third most important social roles for male teenagers were those of house maintenance helper and sports participant, while for the female teenagers they were child care helper and house maintenance helper. The order of the second choices between those of female and male teenagers seems to delineate a difference in sexual appropriateness of roles by the social system of which the sample members are a part. However, the fact that the "house maintenance helper" role was mentioned as a third choice for important social roles for the males, may also indicate an emerging progressive attitude toward gender role delineations among more educated Mexican Americans who comprised the sample .

For Mexican American children, the role of school student was carried over as the most important social role for both males and females, followed in second place by the role of player/sports participant. The third most important social role varied slightly, with the role of house maintenance helper emerging for the males, and that of housekeeping helper emerging for the females. 
This information on roles, though provided by only a small sample of the larger Mexican American population, is important since it can give the occupational therapist working with a Mexican American patient, an idea of the types of roles that allow people of Mexican American descent, at different ages across the lifespan, to function at their best within the structure of their culture and community. Securing such information during an initial intake interview with the patient can be discouraging given the variations which can exist between people of different cultures. Therefore, having some idea as to the importance of the roles of people of different ages in the Mexican American culture, can help guide the therapist in his/her assessment and treatment planning process in concert with the patient, and may also help to promote a basis for a better, more informed therapist-patient relationship.

\section{Goal of Rehabilitation}

The majority of this study's sample indicated their belief that the primary goal of rehabilitation for a person with a disability was equal emphasis on acceptance of limitations resulting from the disability and learning methods and techniques to affect change. The response rate was $88 \%$ of the total sample surveyed, which suggests that most people of Mexican American descent would be favorable toward skills retraining and toward patient/care giver education for learning about their loved one's disability and special techniques to help compensate for the disability. Such receptiveness may reflect a favorable stance toward active participation in working toward therapeutic goals in occupational therapy. 


\section{Use of Community Based Programs for People with Disabilities}

The positive and receptive attitude toward using community based resources was apparent in this study's findings with $84 \%$ of the total sample indicating that they would take advantage of community resources for people with disabilities if someone in their family had a severe disability and was living at home. None of the 25 participants indicated that they would not take advantage of such programs if they were offered, and only $12 \%$ (3 of 25) were undecided.

This information is important to occupational therapists who are planning treatment and working toward discharging a patient with a disability out into the larger community. The majority of the write-in explanations offered a significant message: that care givers/family members can not cope with the responsibility of care alone (financially, emotionally, physically, or because of lack of adequate knowledge) and therefore may need as much help as possible from outside resources to care effectively for their loved one. This message expresses the need for having access to community resources. This stance in support of community programming might also suggest that the subjects participating in this study might hold a more progressive, western stance toward health care and rehabilitation indicated from their decision to use programs from outside the family. This response is quite different from the traditional Mexican American stereotype of Mexican American people being more interdependent and receiving primary support from within the family structure rather from the outside community which is more often the case in American middle class tradition. Perhaps, the majority of those participating in this study 
have been influenced in their responses by the existing standards of the American tradition which do not necessarily support family interdependence, but rather, independence by any means possible.

\section{Implications for the Profession}

Many of the activities which people perform on a daily basis are closely associated with the life/social roles which they hold. It is a rudimentary concept that the culture with which one identifies oneself, greatly influences one's roles as well. Occupational therapists, hoping to gain better rapport and ultimately greater adherence to rehabilitation program plans by patients and their families from other cultures (in this case, the Mexican American culture), may best accomplish this by understanding and accessing information that reflects the important roles held by the patient. In this way, the therapist will be able to set relevant treatment goals to which the patient can relate and feel motivated to follow through.

From the literature it is apparent that the customs, beliefs, attitudes and traditions surrounding health and disability in the Latino culture, of which Mexican Americans are a part, are quite different than those in the Anglo American culture. However, it appears that in the case of this study's Mexican American sample, the ideas regarding health and disability tend to be more progressive than that expressed in the literature. This study's sample is more accepting of the ideals of independence and community support programs which are much more the norm in the United States. Perhaps, this change is the result of a new generation of Mexican Americans who are more educated than their predecessors and more apt to take on more of the characteristics which 
are uniquely "American." Perhaps, this adaptation must come about in order for this new generation of Mexican Americans to survive in the United States (living by the traditions and customs of their culture might not bring them as much acceptance). For whatever reason, the progressive perspectives, attitudes and expectations of this study's sample are evident.

In the realm of rehabilitation, maximum functional independence is the main objective to be sought. In the literature, interdependence appears to be the context in which most Mexican American families function best. In an interdependent relationship, family members are assured of each others support in all matters, even those pertaining to care for sickness or disability. Just as in the Stearns' (1988) study on Vietnamese Americans, most Mexican Americans view the provision of assistance to family members with a disability as an obligation and/or moral responsibility which is expected. Independence is not as relevant a concept in the Mexican American tradition as it is with most Anglo Americans. The results of this study support the idea that an Anglo American occupational therapist (or an occupational therapist who identifies him/herself with the American culture in the United States) who treats a person of Mexican American descent must learn to recognize this difference, and may need to provide patient and family education and training more from the standpoint of the patient's culture, and not as much from the therapist's.

The subjects of this study have directly demonstrated that, if assistance is required for self-care tasks, most Mexican Americans would probably prefer a female within the family to be the caretaker. However, if a therapist was required for self-care training, many would not have a preference for the gender of the 
therapist.

This study, like its predecessor (Stearns, 1988), was developed on the basis that the meaning of various activities of daily living (ADL) can be acknowledged through their importance in supporting valued social roles. The results of this study demonstrated strong support for the role of "values teacher" for both younger and older women and men in the Mexican American community. For male and female teenagers and children, the role of "school student" was very important.

The results of this study also suggested that Mexican American people who have disabilities would be most willing to participate in a rehabilitation program that would place equal emphasis on acceptance of limitations resulting from the disability and on learning methods and techniques to make changes that would enable better quality in function and performance. There was also strong support for the use of community-based programs for people with disabilities demonstrated in this study with many subjects showing concern concern over the family's ability to work, to cope emotionally, and handle care for the patient all in one day.

The results of this study, just as in Stearns' (1988), demonstrate the important role occupational therapists can take in influencing the position of the patient's family toward assisting a family member with a disability in daily activities which contribute to the social roles for the patient. The results of this study and that of Stearns (1988) vary with regards to who makes decisions for amount of assistance provided for a person with a disability. Stearns (1988) found that the eldest family member in coordination with the attending physician 
was the primary person in making decisions with regards to amount of assistance provided for people of Vietnamese descent. The results of this study, however, demonstrate that therapists must work primarily with the patient with the disability, in deciding upon workable, functional treatment goals and amount of assistance to be provided when working toward these goals. The patient's family, especially the oldest member (regardless of gender), is also important in the decision making process. Yet, according to the Mexican American sample of this study, the eldest is not the primary decision maker regarding how much assistance the person with the disability should have. Therefore, the results of this study imply that the therapist must learn to recognize the types of limitations such as time, money, work schedules, available transportation, conflicting ideas surrounding these, and priorities of the patient and their family. The therapist must then work with these in ways that can bring forth the most benefit to all involved.

With an idea of important social roles held by the Mexican American patient in their family and community, the occupational therapist can be better prepared for selecting relevant treatment activities. Ideally, respect for an individual's culture will encourage ethnic minorities to seek the occupational therapy care they need, and help them to feel more comfortable utilizing and complying with such treatment for their disability. As Caudle (1993) pointed out, "Mexican American [patients] have responded more readily to directions and treatments when it was evident that the provider was incorporating cultural beliefs into the plan of care" (p.44). 


\section{Recommendations}

Supporting the relevancy of this study, just as in Stearns (1988) study, was the apparent lack of research available on the attitudes and perspectives of Mexican Americans toward disability. With the growing number of Mexican Americans currently living in, being born in, and coming to the United States, the need for more research on this segment of the American community is important (Caudle, 1995; Giachello, 1985). For occupational therapists working in San Jose, California, contact with patients of Mexican American descent is very common, and therefore it is important for the therapist to have some working knowledge about relevant areas for assessment, as well as types of activities and importance roles held by the patient before treatment is begun.

A recommendation for future study regarding this topic would be obtaining a larger, less educated, not necessarily English speaking, more randomized sample in order to increase the chances for statistical analysis of the data and to eliminate possible bias.

If future study of this topic should warrant the use of a questionnaire, it is recommended that the researcher obtain a more prototypical sample and find translation services well in advance in order to assure culturally sensitive and reliable means of data collection and analysis. With this in place, the researcher can also be more confident of the relevancy of the information obtained from the study. Upon obtaining the final count of questionnaires from this study, it came to the attention of this researcher, that a large number of subjects were unsure of the meaning of certain questions, as evidenced by vague, incomplete, or inaccurate answers given. Some data were unusable as a result of lack of 
clarity. More reliable data could perhaps be secured by the use of face to face interviews.

Another suggestion for future research on this topic would be to include more questions on family roles within the social/kinship structure and about how disability affects one's social and emotional roles within the family (i.e. if disabled, what happens to your role as a son/daughter, mother/father?). The questions on the current questionnaire primarily looked at independence or dependence for performing basic physical functions without the deeper pursuit of social and emotional functions. However, it would be very important for an occupational therapist to understand the family social system and the role the family plays in the patient's daily social and emotional life as a person with a disability. It might also be important for the researcher to find out if the social/emotional roles served by the family provide enough support to make seeking the support of outside community programs that have been set up in the United States to encourage more independent functioning or functioning with less family support and more program support irrelevant and /or unnecessary. It would seem logical, as per the literature on Mexican Americans, that the family's interdependence provides the best healing powers and is the best resource to the patient. The traditional curandero/healer in the Mexican American community seems to place more emphasis on the family as a healing agent and support system in and of itself in order to derive therapeutic benefits. Perhaps, with this in mind, occupational therapists can best serve Mexican American clientele by being more aware and respectful of the family's function in this arena. 
Finally, there are some last issues which could be dealt with in future studies of this topic: What happens with role fulfillment within the family, as the person with a disability comes to the United States? How do the roles of the person with a disability change or stay the same? And, if one becomes disabled in the Mexican American community and family, does the person with a disability tend to focus more or less than the typical American on work fulfillment, with work, in America, being synonymous with increased self-worth? 


\section{REFERENCES}

Anderson, P. P. (1989). Issues in serving culturally diverse families of young children with disabilities. Early Child Development and Care, 50, 167 188.

Angel, R. (1984). The costs of disability for Hispanic males. Social Science Quarterly, 65, 426-443.

Arnold, B., \& Orozco, S. (1987). Physical disability, acculturation and family interaction among Mexican Americans. In B.R. Arnold (Ed.), Disability, rehabilitation and the Mexican American (pp. 40-60). Edinburg, TX: Pan American University.

Barney, K. (1991). From Ellis Island to assisted living: Meeting the needs of older adults from diverse cultures. American Journal of Occupational Therapy, 45, 586-593.

Bauwens, E. \& Anderson, S. (1992). Social and cultural influences on health care. In M.Stanhope, \& J. Lancaster (Eds.), Community health nursing process and practice for promoting health . St. Louis: Mosby-Yearbook.

Berlin, E. and Fowkes, W. (1983). A teaching framework for cross-cultural health care: application in family practice. The Western Journal of Medicine, 139(6), 130-134.

Casas, J., \& Ponterotto, J. (1991). Handbook of racial/ ethnic minority counseling research. Springfield, IL: Charles C. Thomas.

Caudle, P. (1993). Providing culturally sensitive health care to Hispanic clients. Nurse Practitioner, 18, 40-50. 
Clark, M. (1983). Cultural context of medical practice. Western Journal of Medicine, $139(6), 2-6$.

Cruz, D. (1979). Outreach problems in Puerto Rico. In G. Dixon \& C. Bridges (Eds.), On being Hispanic and disabled: The special challenges of an under served population (pp. 33-34). Washington, DC: Partners of the Americas.

Cuellar, J. (1988). Hispanic elders. In L.A. Llorens (Eds.), Health care for ethnic elders: The cultural context (pp. 30-32). Stanford, CA: Stanford Geriatric Education Center.

Davidson, H. (1991). Performance and the social environment. In C. Christiansen, \& C. Baum (Eds.), Occupational therapy: overcoming human performance deficits (p.148). Thorofare, NJ: SLACK Inc.

Dillard, M., Andonian, L., Flores, O., Lai, L., MacRae, A., \& Shakir, M. (1992). Culturally competent occupational therapy in a diversely populated mental health setting. American Journal of Occupational Therapy, 46, 721-726.

Downes, N. (Ed.). (1994). Ethnic Americans: For the health professional. Dubuque, lowa: Kendall-Hunt.

Fitzgerald, M. (1992). Multicultural clinical interactions. Journal of Rehabilitation, 58, 38-42.

Gann, L., \& Duignan, P. (1986). The Hispanics in the United States: A history. Boulder, CO: Westview Press.

Giachello, A. (1985). Hispanics and health care. In P. Cafferty \& W. McCready. (Eds.), Hispanics in the United States: A New Social Agenda (pp. 159-194) . New Brunswick, NJ: Transaction Books. 
Guralnik, D. (Ed.) . (1980). Webster's New World Dictionary (2nd ed.). New York: Simon \& Schuster.

Hanline, M., \& Daley, S. (1992). Family coping strategies and strengths in Hispanic, African-American, and Caucasian families of young children. Topics in Early Childhood Special Education, 12 (3), 351-365.

Harris, P., \& Moran, R. (1987). Managing cultural differences (2nd ed.) . Houston, TX: Gulf.

Harward, N. (1969). Socioeconomic and other variables related to rehabilitation of Mexican Americans in Arizona. Final Report. Tempe: Arizona State University.

Hopkins, H. L., \& Smith, H. D. (Eds.). (1988). Willard and Spackman's occupational therapy. Philadelphia: J.B. Lippincott Company.

Kapur, S. (1986). Non-traditional career approaches for disabled nonwhite persons. In S. Walker, F.Z. Belgrave, A.M. Banner, \& S. Nicholls (Eds.), Equal to the challenge: Perspectives, problems and strategies in the rehabilitation of the non-White disabled (pp. 104-110). Washington, DC: The Bureau of Educational Research, School of Education, Howard University.

Kiernat, J.M. (Ed.) . (1991). Occupational therapy and the older adult: A clinical manual (pp. 11-14) . Gaithersburg, MD: Aspen.

Kraft, W. (1979). Normal and mad. Duquesne Studies in Phenomenological Psychology, 3, 7-14.

Lea, A. (1994). Nursing in today's multicultural society: a transcultural perspective. Journal of Advanced Nursing, 20, 307-313. 
Lewis, M. (1991, February 27). Minorities take off in county census. San Jose Mercury News, p. A1.

Linkowski, D. (1987). The acceptance of disability scale. Washington, DC: Rehabilitation Research and Training Center, George Washington University Medical Center.

Linskey, A., Arnold, B., \& Hancock, S. (1983). Barriers to access and utilization of services by the handicapped Hispanic. In Special rehabilitation and research needs of disabled Hispanic persons (pp. 27-38). Edinburg, TX: National Institute of Handicapped Research and President's Committee on Employment of the Handicapped.

Maduro, R. (1983). Curanderismo and Latino view of disease and curing. The Western Journal of Medicine, 139(6), 868-874.

Marion, R. L. (1980). Communicating with parents of culturally diverse exceptional children. Exceptional Children, 46, 616-623.

McLemore, S., \& Romo, R. (1985). The origins and development of the Mexican American people. In R. de la Garza, F. Bean, C. Bonjean, R. Romo, \& R. Alvarez (Eds.), The Mexican American experience: An interdisciplinary anthology (pp. 3-32). Austin: University of Texas Press.

Ogbu, J. (1987). Cultural influences on plasticity in human development. In J.J. Gallagher \& C.T. Ramey (Eds.), The malleability of children (pp.59-62). Baltimore, MD: Paul H. Brookes Publishing Co.

O'Toole, M. (Ed.). (1992). Miller-Keane Encyclopedia and Dictionary of Medicine, Nursing, and Allied Health (5th ed.). Philadelphia: W.B. Saunders Co. 
Padilla, R. (1994). Cultural aspects in occupational therapy. Occupational Therapy Association of California, 19(3), 14-15.

Pope-Davis, D.B., Prieto, L.R., Whitaker, C.M., \& Pope-Davis, S.A. (1993). Exploring multicultural competencies of occupational therapists: Implications for education and training. The American Journal of Occupational Therapy, 47. 838-843.

Reilly, M. (1974). Play as exploratory learning. Los Angeles: Sage.

Rivera, O. A. (1983). Vocational rehabilitation process and Hispanic culture. The special rehabilitation and research needs of disabled Hispanic persons. Washington, DC: National Institute of handicapped Research and the President's Committee on Employment of the Handicapped.

Schreiber, J. \& Homiak, J. P. (1981). Mexican Americans. In A. Harwood (Ed.), Ethnicity and medical care (pp. 22-23). Cambridge, MA: Harvard University Press.

Short, P. \& Lefkowitz, D. (1992). Encouraging preventative services for low-income children: The effect of expanding Medicaid. Medical Care, 30, 766780 .

Smart, J.F. (1993). Level of acculturation of Mexican Americans with disabilities and acceptance of disability. Rehabilitation Counseling Bulletin. 36(4).199-209.

Smart, J.F. \& Smart, D. W. (1991). Acceptance of disability and the Mexican American culture. Rehabilitation Counseling Bulletin, 34(4), 357-367.

Stearns, D. R. (1988). Vietnamese perspectives on independence and role fulfillment of the disabled. Unpublished master's thesis, San Jose State 
University, California.

Suazo, A. (1986). The emerging role of disabled Hispanics. In S. Walker, F. Z. Belgrave, A. M. Banner, \& R.W. Nicholls (Eds.), Equal to the challenge: Perspectives, problems and strategies in the rehabilitation of the nonwhite disabled (pp. 34-35). Washington, DC: Howard University Bureau for Educational Research.

Wilson, C., \& Gutierrez, F. (1985). Minorities and media: Diversity and the end of mass communication. Beverly Hills, CA: Sage Publications.

World Health Organization. (1980). International classification of impairments, disabilities, and handicaps: A manual of classification relating to consequences of disease. Geneva: World Health Organization. 
APPENDIX QUESTIONNAIRE 


\section{Perspectives On Disability Among Mexican Americans -adapted from Stearns (1988)}

Instructions: Please read the following questions carefully. Each question may ask for one, two or three answers and/or explanations.

Demographic data base:

Of Mexican American origin? yes no

Your current age (in years)?
- 0-19 20-39 40-59 over 60

Your gender: Male Female

Your age when you moved to the United States (in years)? _ lived here since birth 0-19 20-39 40-59 over 60

What is your present level of education?

Your religion?

Roman Catholic Pentecostal Seven Day Adventist Baptist Buddhist Not associated with any particular religious group Other. Please list

I. Perspectives on disability as a disabled person

Please answer the following questions as if someone you knew of your gender and age group had a severe disability. (For example, if that person had a stroke.)

1. If he/she (the person you knew) had a severe disability, which three activities listed below would you feel the most important for him/her to be able to do him/herself?
Eating Bathing Toileting Meal preparation House maintenance House keeping Child care Dressing Operating a car or wheelchair Grooming Other. Please list

2. With which three activities would you think he/she would be most willing to accept help with from someone else?
Meal preparation Toileting Dressing House keeping Grooming Other. Please list Child care House maintenance Bathing 
3. With which three activities might he/she feel obligated to accept help with from someone else?

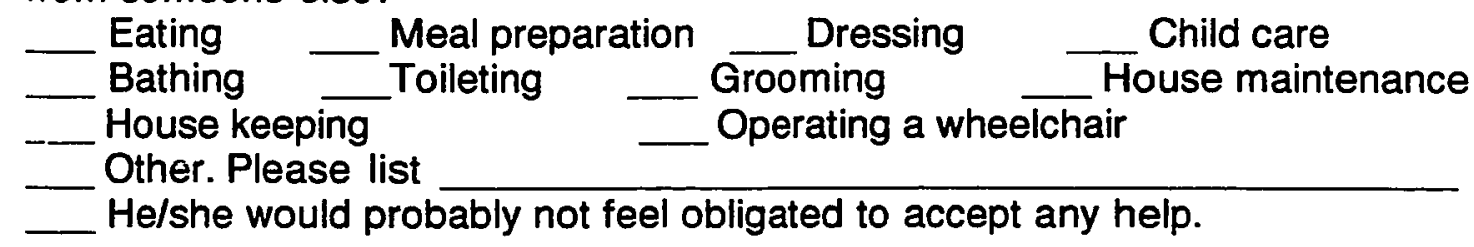

4. If he/she required help at home for self-care activities (eating, dressing, bathing, toileting, grooming), who would you expect he/she would prefer to assist him/her? (Select one answer only for this question.)

_ A male in the family A female in the family A male attendant, not related to the family A female attendant, not related to the family Other. Please list.

5. If helshe required training from a therapist for self-care activities (eating, dressing, bathing, toileting, grooming), would you expect he/she would prefer that person be a Male Female Either male or female (does not matter)

\section{Perspectives on disability as a parent}

Please answer the following questions as if someone you knew of your gender and age group had a child with a severe disability.

1. If this person's son/daughter had a severe disability, would you expect the parents to help him/her with certain activities?

Please explain Yes No I am not sure.

If you believe they would help, with which three activities would you expect them to lend assistance?

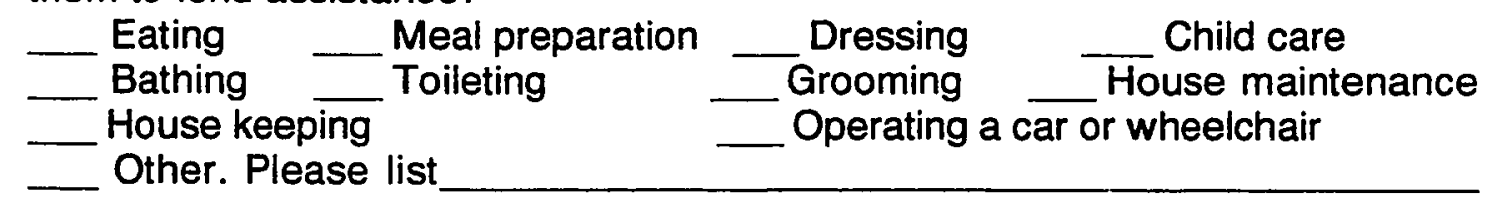


2. If this son/daughter did not want parental assistance, would you expect the parents to allow him/her to do these activities independently?

Please explain 
2. If the person's father/mother did not want assistance from the son/daughter, would you expect the son/daughter to allow their father/mother to do these activities independently?

Please explain__ No

3. Which two people do you think would have the most influence over the son/daughter's decision to help or not help their disabled parent with these activities?

The disabled father/mother

The attending Western medical doctor

The attending traditional Hispanic healer/doctor/curandero

The attending therapist working with the parent on self-care activities

The oldest family member, regardless of sex

A religious leader

Other.

Please list

IV. Roles in community life

Optimal rehabilitation for the person with a disability depends on the understanding of the community to which that person belongs to. It is very important to plan treatment that will address the needs of the individual with the disability in his/her home and community. Satisfying social roles and expectations are a vital part of success in the home and community environments.

Please answer the following questions regarding roles for the non disabled population.

1. In your opinion, what are the three most important roles for a man?

A wage earner

A values teacher A money manager A house maintainer Other.
A child and/or grandparent caretaker

A protector

A housekeeper

A cook

Please list 
2. In your opinion, what are the three most important roles for a woman?

A wage earner A values teacher A housekeeper Other.
A child and/or grandparent caretaker

A protector

A house maintainer
A money manager A cook

Please list

3. In your opinion, what are the three most important roles for an elderly woman?

A financial advisor

A values teacher

A money manager a cook Other. Please list
A child caretaker

A protector

A housekeeper
A house maintainer

4. In your opinion, what are the three most important roles for an elderly man? A financial advisor A values teacher A money manager A house maintainer Other. Please list A child caretaker

A protector A housekeeper a cook

5. In your opinion, what are the two most important roles for a male teenager?

A school student

A child care helper

A house maintenance helper

A wage earner

Other. Please list
A sports participant

A housekeeper

A cook

6. In your opinion, what are the two most important roles for a female teenager?

A school student

A child care helper

A cook

Other. Please list
A sports participant A housekeeper A wage earner
A house maintainer

7. In your opinion, what are the two most important roles for a boy child? A player/sports participant A housekeeping helper A cooking helper Other. Please list A school student A child care helper A house maintenance helper A wage earner 
8. In your opinion, what are the two most important roles for a girl child?

A player/sports participant

A child care helper

A house maintenance helper

A wage earner

Other. Please list
A school student

A housekeeping helper

A cooking helper

\section{Concluding questions about disability}

1. In your view, what is the primary goal of rehabilitation therapy for a person with a disability? (please select one answer only)

Emphasis on acceptance of limitations resulting from the disability (with minimal learning of methods and techniques to affect change).

Equal emphasis on acceptance of limitations resulting from the disability and learning methods and techniques to affect change. Emphasis on learning methods and techniques to affect change (with minimal acceptance of limitations resulting from the disability). Other.

Please explain

2. Do you have a disabled person in your family? Yes No If yes, who? (Check more than one if applicable.) A parent An uncle/aunt A child A spouse A grandparent Other. Please list A relative by marriage

A cousin A niece/nephew

3. If someone in your family had a severe disability and was living at home, would you make use of community based programs for people with disabilities? Please explain No I am not sure

Thank you very much for participating in this study. Your time is much appreciated!

When you turn in your questionnaire, you are indicating consent to be a participant in this study. 
To:

Dorothy Stearns, MS, OTR

Department of Veteran Affairs

Palo Alto VA Medical Center

3801 Miranda Ave.

Palo Alto, CA 94304

From:

Michelle M. Auer

9225 East Tanque Verde RD \#37203

Tucson, AZ 85749

This letter comes as a request for permission to adapt and reprint the following:

the questionnaire for:

Stearns, Dorothy R. (1988). Vietnamese perspectives on independence and role fulfillment of people with disabilities. Unpublished master's thesis, San Jose State University, San Jose, California.

This questionnaire will be adapted for use with a Mexican American subject sample for the thesis:

Auer, Leslie Michelle M. (1995). Mexican American perspectives on independence and role fulfillment for people with disabilities: an adapted study. master's thesis, San Jose State University, San Jose, California.

mark an $\mathrm{x}$ in one of the following spaces:

Permission granted

Permission not granted

If permission granted, is there any comments/disclaimers you would like

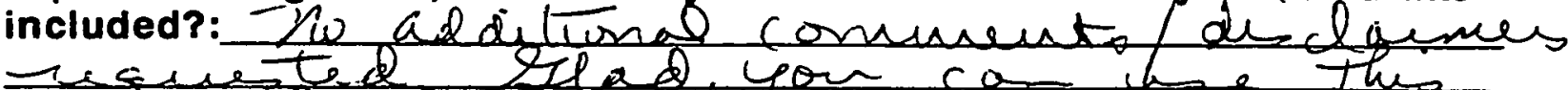

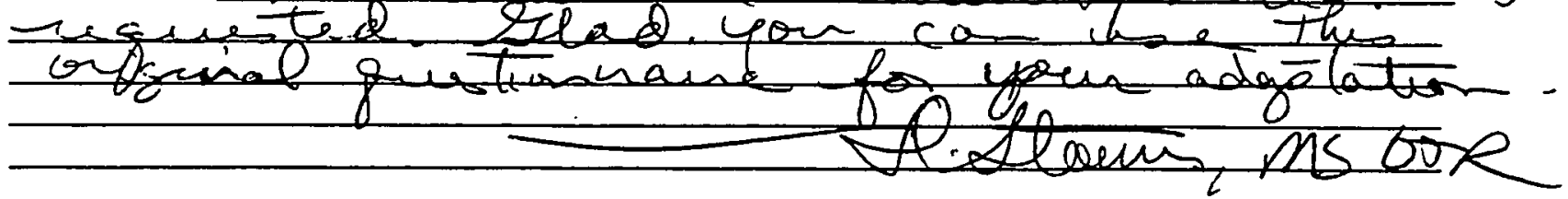

